\title{
1 A model for composing meat replacers: reducing the 2 environmental impact of our food consumption 3 pattern while retaining its nutritional value
}

4

5 Klara Van Mierlo*

6 Sonja Rohmer

7 Johanna C. Gerdessen

8

9 Operations Research and Logistics, Wageningen University, PO Box 8130, 6700 EW Wageningen, 10 The Netherlands 


\section{Abstract}

12 Current food consumption patterns have a substantial impact on our environment and are thus

13 considered unsustainable. In the context of global warming and a rising world population, shifting

14 from meat towards more plant-based products holds potential to reduce the environmental impact of our food consumption. Replacing meat in the diet, however, requires compensation through other products that are able to provide the important nutrients present in meat (protein, iron, zinc and vitamin B12). This study applies linear programming techniques with the aim to compose meat replacers, with equivalent nutritional value to meat (using chicken and beef as a reference), minimizing the environmental impact with regards to climate change, land use, water use and fossil fuel depletion. A life cycle approach was used to quantify the environmental impacts. Particular attention was given to protein quality and the relative quantities of essential amino acids. The results show that soy is a preferred ingredient due to its favorable amino acid profile. Among the different scenarios investigated, the vegan replacers, with reductions of up to $87 \%$, have the largest potential for impact reduction for all indicators except water use. Insect-based replacers have the largest potential for water use reduction (up to 47\%), but show relatively high fossil fuel depletion values. The smallest improvement potential is observed with regards to fossil fuel depletion, with some values even $45 \%$ higher than the values for meat. Furthermore, it is not possible to obtain equivalent nutritional values to beef without using fortifications.

\section{Key words}

Life cycle assessment (LCA) 


\section{Introduction and background}

Food is a vital part of our lives, however current consumption and production patterns pose a threat to the natural environment by contributing to global warming, resource depletion and the extinction of species (Garnett, 2013). The food system as a whole accounts for an estimated 20-30\% of the global greenhouse gas emissions (Vermeulen et al., 2012) while, within food consumption patterns, meat and dairy products are the main contributors to environmental impacts (Notarnicola et al., 2017; Steinfeld et al., 2006). Among the different types of meat, beef has the largest and chicken the smallest environmental impact in terms of climate change, land use and fossil fuel depletion (Hallström et al., 2015). Given a growing population and an increase in wealth the demand for food and meat is predicted to increase by around $70 \%$ by 2050 for food and by 2030 for meat (Fiala, 2008; FAO, 2009). This rise in demand combined with the sustainability aspects faced by the food system, poses major challenges for the future and calls for measures to countervail some of these effects.

Over recent years, scientific literature increasingly focused on the environmental impact of food and dietary consumption patterns. In this context, Hallström et al. (2015) conducted a literature review to assess the impact of dietary change on the environment, comparing 14 articles (published in the period from 2009 to 2014) with a focus on climate change and land use. Furthermore, research has investigated the environmental impact of a number of different dietary scenarios, showing that vegan and vegetarian scenarios are most promising for lowering environmental impacts (Meier and Christen, 2012; Dooren et al., 2014, Berners-Lee et al., 2012). Thus, replacing meat within food consumption patterns and shifting towards more environmental friendly products could reduce the environmental impact of our food system (Health Council of the Netherlands, 2011).

An often used method to evaluate the environmental impact of food products is Life Cycle Assessment (LCA) (Mogensen et al., 2009) (see appendix B for a description of the LCA method). Several studies apply LCA to compare the environmental impact of meat products with the environmental impact of meat replacers, based on indicators like climate change, land use, water use, ozone layer depletion, human toxicity, acidification and eutrophication. Using an LCA approach, Smetana et al. (2015) show that the environmental impacts of different meat replacers are lower than the environmental impact of chicken, except for lab-grown and mycoprotein-based meat replacers, due to a high energy demand for medium cultivation. Zhu \& van Ierland (2004) show similar results, concluding that a pea-based meat replacer has a lower environmental impact than pork in terms of the studied environmental impact indicators.

However, when replacing meat, it should be ensured that the nutritional requirements of the consumer are still met. Meat is an important source of high quality protein, iron, zinc and vitamin B12 (Bender, 1992). Protein quality is determined by the relative quantities of essential amino acids, i.e. amino acids that cannot be synthesized by the human body (Bender, 1992). In particular, protein quality is fully 
determined by the amino acid that is present in the lowest amount relative to human requirements, the so-called limiting amino acid. The other amino acids cannot compensate for a shortage of the limiting amino acid, so if the limiting amino acid is present in low quantities the nutritional quality of the protein will be seriously affected (FAO/WHO/UNU, 2002). Food consumption patterns should therefore contain every essential amino acid in an amount that meets the corresponding human requirements. Meat proteins are of good quality because they contain all the essential amino acids in a proportion resembling that of the human needs (Asgar et al., 2010).

Most of the important nutrients of meat can also be found in plant-based products. However, the nutrients are present in different proportions and often in different forms (Broekema \& Blonk, 2009). Moreover, plant-based products do not contain vitamin B12 (Broekema \& Blonk, 2009) and have a less favorable amino acid composition than meat (Asgar et al., 2010). An option to meet the requirements for iron, zinc and vitamin B12 in a meatless food consumption pattern is to combine plant-based products with animal-based products, like eggs and dairy products. Another option is to supplement plant-based products with fortifications (i.e. nutrient supplements) (Broekema \& Blonk, 2009).

Combining environmental constraints with nutritional considerations, literature increasingly recognises modeling techniques (such as linear programming) as a tool to optimise dietary intake with regards to different criteria. Examples of such diet models, taking into account nutritional as well as environmental aspects using linear programming, are found in MacDiarmid et al. (2012), Tyszler et al. (2016), Tyszler et al. (2014) and Wilson et al. (2013).

MacDiarmid et al. (2012) and Tyszler et al. (2016) have shown that the elimination of meat and dairy products has the biggest effect on decreasing environmental impacts, but that an entirely vegan diet might prove difficult in terms of acceptance within the population and therefore might not be adopted. Tyszler et al. (2014) concluded that a scenario in which meat is replaced with soy-based products has a lower environmental impact, however an additional serving of fish has to compensate for a lack of limiting amino acids as the replacement product is not nutritionally equivalent to meat. Wilson et al. (2013) show a slightly higher environmental impact for the vegan diet in comparison to other scenarios investigated, although they illustrate that a shift from meat towards more plant-based foods can have a positive effect on cost, health and environmental objectives.

The study of Temme et al. (2013) shows that the environmental impact of the diet can be reduced by replacing meat and dairy products with plant-based products without having a negative impact on the iron intake while even lowering saturated fatty acids. One of the limitations of the study, however, is that the lower absorption rate of heme iron was not considered. Davis et al. (2010) investigate the environmental impact of four different meal scenarios with different protein sources. While their findings show that the plant-based alternative protein source (pea-burger) has a lower environmental 
impact, the study does not elaborate on the protein quality of this alternative. The study of Sonesson et al. (2017), comparing different functional units based on protein content in the context of LCA, however, shows that protein quality and digestibility is of importance and affects the environmental impact per unit.

110 While research shows that plant-based diets generally have a lower environmental impact, culture and 111 acceptance plays an important role when comparing and adopting these dietary scenarios. Replacing

112 meat by unprocessed products like legumes or pulses changes the component structure of the meal and

113 might therefore impede acceptance, whereas using instant meat substitute can facilitate the

114 replacement of meat due to increased convenience, low cooking skill requirements and maintaining

115 the component structure of the meal (Schösler et al., 2012). From a nutritional perspective it is

116 however important to compare the actual nutritional contribution of such replacement products. While

117 the diet is considered the best food unit to evaluate nutritional intake (Van Kernebeek et al., 2014), we

118 believe there is a benefit of designing replacement products that can provide the equivalence of the

119 important nutrients of meat and at the same time make it easy and convenient for the consumer to

120 switch from meat to a more sustainable product. Thus, the aim of this study is to find the optimal

121 combination of non-meat ingredients to compose meat replacers that have an environmental impact as

122 low as possible and a comparable nutritional value to meat. Replacing meat with these meat replacers

123 could reduce the environmental impact of our food system without compromising the nutritional

124 requirements of the population.

125 The results of this study are useful for producers of meat replacers that want to reduce environmental

126 impacts and offer products that contain the equivalence of the valuable nutrients present in meat.

127 Consumers that are concerned about the environmental impact of their consumption can integrate

128 these products in their food consumption pattern as a convenient replacement for meat. Furthermore,

129 the results can be useful for governments that want to estimate the potential impact of dietary shift

130 from meat to meat replacers. 


\section{Methods}

133 This study uses a linear programming model to find the composition of meat replacers that have an environmental impact as low as possible and provide the equivalence of the important nutrients in meat.

\subsection{Scenarios: four types of meat replacers}

We modelled four types of meat replacers: vegetarian, vegan, insect-based and fortification-free. The vegetarian meat replacer may contain animal-based ingredients, but no insects. The vegan meat replacer may only contain plant-based ingredients. The insect-based meat replacer has insects as its main protein source. The fortification-free meat replacer may not contain any fortification (i.e. supplements of vitamins or minerals). Beef and chicken are used as references in the model, since they represent the largest and the smallest environmental impact of meat, respectively.

Two kinds of results are presented, for which Figure 1 defines the boundaries: ingredient results and end product results. The ingredient results (full line box) are calculated by summing the environmental impacts of the selected ingredients up to the point of processing them into the meat replacer. For some ingredients, this includes a processing step to convert raw materials into ingredients (e.g. from soy beans to soy flour). Other ingredients are used directly in the form they are produced in the agricultural production step (e.g. eggs).

Ingredient results are converted into end product results (dashed line box) by adding the environmental impact of the processing steps that convert the ingredients into a meat replacer. From consumer perspective, the end products are replacements for the references (raw chicken and raw beef steak), since they all need the same home preparation, e.g. baking.

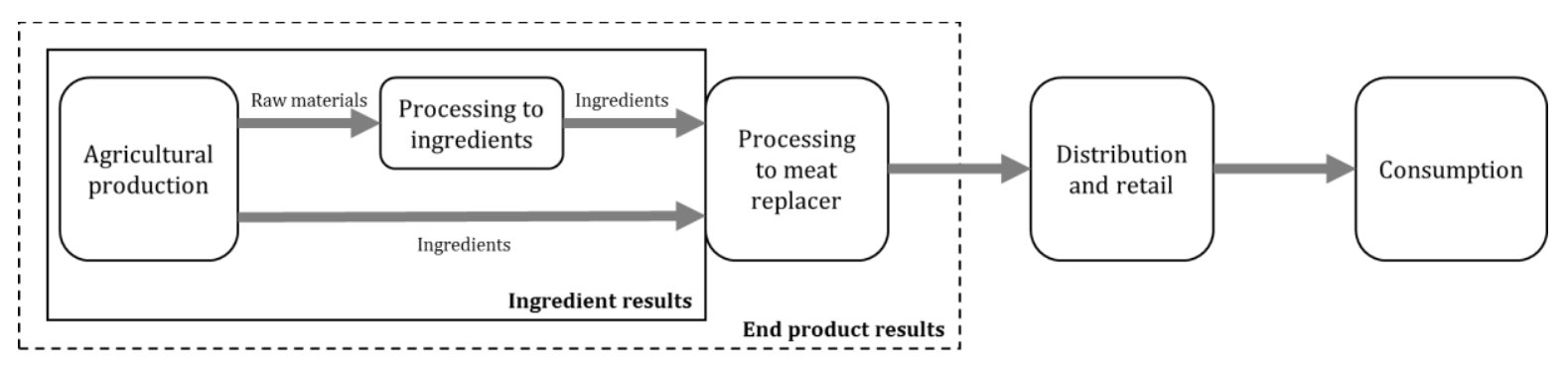

Figure 1. System boundaries for the ingredient results (full line box) and end product results (dashed line box). The grey arrows indicate transportation steps. The ingredient results (full line box) are calculated by summing the environmental impacts of the selected ingredients up to the point of processing them into the meat replacer. End product results also comprise the environmental impact of the processing steps that convert the ingredients into a meat replacer.

\subsection{Selection of nutrients, environmental impacts and ingredients}

\subsubsection{Nutrients}

The model includes the nutrients for which meat is an important source: protein, iron, zinc and vitamin B12. In order to ensure sufficient protein quality, protein is included on the level of individual essential amino acids: lysine, leucine, isoleucine, tryptophan, threonine, methionine + cystine, 
phenylalanine + tyrosine and valine. Iron is expressed in non-heme iron, see Appendix A. The required contents of protein, iron, vitamin B12 and zinc are based on the contents in chicken and beef. The required contents of essential amino acids are based on the human requirements for these amino acids, see Appendix A.

\subsubsection{Environmental impacts}

Based on a literature review of LCA studies (see appendix B), we selected suitable environmental impact indicators. Since this study focuses on environmental impact, indicators that only affect the Area of Protection (AoP) human health $(\mathrm{H})$ are left out. For the AoP natural environment, indicators with the following characteristics are selected:

- frequently used

- classified in category 1 of Hauschild et al. (2013)

- related to food production

Climate change is selected as an impact indicator, satisfying all these requirements. In this study, climate change is defined as Global Warming Potential (GWP), expressed in $\mathrm{kg} \mathrm{CO}_{2}$ equivalents. Although eutrophication and acidification are related to food production and are often used, they are not selected because they only affect the local environment and because their assessment method is not of sufficient quality (see table B-1). For the AoP natural resources, fossil fuel depletion and water use are selected because of their relation to food processing. Energy use is also often used as indicator, but includes other energy forms than fossil energy sources, like nuclear and renewable energy (Weidema et al., 2013). In this study, the indicator fossil fuel depletion is used, referring to the use of fossil fuels like coal, oil and natural gas (Goedkoop et al., 2013). We made this choice because we want to focus on the depletion of natural resources, which are, in terms of energy, mainly fossil fuels (Goedkoop et al., 2013). Land use does not follow a standardized approach (Smetana et al., 2015), which is demonstrated by the fact that it is classified in the third category in the article of Hauschild et al. (2013). However, it is an important impact category when it comes to feed and food (Smetana et al., 2015) and is used in a large number of LCA studies of food products. That is why land use is selected. In conclusion, four impact indicators are selected: climate change, land use, water use and fossil fuel depletion.

\subsubsection{Ingredients}

The model uses ingredients that are sources of the same nutrients as meat, while having a lower environmental impact. Legumes and wheat are included, because they are good sources of protein, iron and zinc (Broekema \& Blonk, 2009; Voedingscentrum, 2016). They are commonly used in the form of flour, protein concentrate or protein isolate (Averink, 2015). Eggs and dairy products are included as they are good sources of high quality protein, iron, zinc and vitamin B12 

interest for use as meat replacers. They are generally high in protein, vitamins and minerals (Bukkens, 1997). The production of mealworms results in a lower climate change value and requires less land than the production of meat (Oonincx \& de Boer, 2012). Therefore, two sorts of insects, the mealworm (Tenebrio molitor) and the super worm (Zophobas morio), are included in the model. Iron-, zinc- and vitamin B12 fortifications are included to ensure that the requirements for these nutrients can be met. The full list of ingredients, with their nutrient contents and environmental impacts, can be found in Appendix C.

\subsection{Data inputs}

\subsubsection{Data collection}

The main nutritional data were retrieved from the NEVO database (RIVM, 2013). Data that are not available in this database were retrieved from the online nutrient database of the United States Department of Agriculture (USDA, 2016) and from literature (Broekema \& Smale, 2011; Friedman, 1996; Davis et al., 1994; FAO/INFOODS, 2013; Flindall). Life cycle environmental impacts of the

213 studied products were obtained from various sources as shown in Table 2.

Table 1. Consulted studies, their studied products and their system-and geographical boundaries. The last

215 column indicates which environmental impact values were obtained from the studies.

\begin{tabular}{|c|c|c|c|c|}
\hline Study & Studied product & System boundary & $\begin{array}{l}\text { Geographical } \\
\text { boundary }\end{array}$ & $\begin{array}{l}\text { Obtained environmental } \\
\text { impact values }\end{array}$ \\
\hline (Blonk et al, 2007) & Meat (fresh) & From crade to farm gate & The Netherlands & $\begin{array}{l}\text { Climate change, land use, } \\
\text { fossil fuel depletion }\end{array}$ \\
\hline $\begin{array}{l}\text { (Broekema \& Smale, } \\
\text { 2011) }\end{array}$ & Legumes & From cradle to factory gate & $\begin{array}{l}\text { Processing in the } \\
\text { Netherlands, } \\
\text { cultivation in most }\end{array}$ & $\begin{array}{l}\text { Climate change, land use, } \\
\text { fossil fuel depletion }\end{array}$ \\
\hline $\begin{array}{l}\text { (Mollenhorst et al, } \\
\text { 2007) }\end{array}$ & Eggs & $\begin{array}{l}\text { Cradle to farm gate, average } \\
\text { of four egg production } \\
\text { systems }\end{array}$ & The Netherlands & $\begin{array}{l}\text { Climate change, land use, } \\
\text { fossil fuel depletion }\end{array}$ \\
\hline $\begin{array}{l}\text { (van Middelaar et al., } \\
\text { 2011) }\end{array}$ & Cheese & Cradle to factory gate & The Netherlands & $\begin{array}{l}\text { Climate change, land use, } \\
\text { fossil fuel depletion }\end{array}$ \\
\hline $\begin{array}{l}\text { (Oonincx \& de Boer, } \\
\text { 2012) }\end{array}$ & Meal worms & Cradle to farm gate & The Netherlands & $\begin{array}{l}\text { Climate change, land use, } \\
\text { fossil fuel depletion }\end{array}$ \\
\hline $\begin{array}{l}\text { (Mekonnen \& } \\
\text { Hoekstra, 2011) }\end{array}$ & Legumes & Cradle to farm / factory gate & Global & Water use \\
\hline $\begin{array}{l}\text { (Mekonnen \& } \\
\text { Hoekstra, 2013) }\end{array}$ & $\begin{array}{l}\text { Meat, eggs, cheese, } \\
\text { meal worms }\end{array}$ & Cradle to farm / factory gate & Global & Water use \\
\hline
\end{tabular}

217 When data is used from different LCA studies, the system boundaries, functional unit and allocation

218 method should ideally be the same (de Vries \& de Boer, 2010). All the consulted studies use a

219 functional unit of $1 \mathrm{~kg}$ of product and applied economic allocation. As can be seen in Table 1, the

220 system boundaries of all the studies start 'from cradle', which means that the environmental impact

221 includes all the upstream life cycles steps, starting at the primary cultivation step. The boundaries are

222 until the farm or factory gate, which indicates that life cycle steps are taken into account up to the 223 point that the products leave the farm or factory (Blonk Agri Footprint BV, 2015). As presented in

224 Figure 1, the environmental impacts of all the ingredients go up to the point of processing into the 
meat replacer. This corresponds with the farm and factory gate of the consulted studies. The geographical boundaries of all the studies relate to the Netherlands, except for the water footprint network. This study did not provide sufficient local data for the Netherlands, therefore a global average is used.

Data concerning applied processes to convert the ingredients into meat replacers were obtained from a producer of meat replacers (Averink, 2015). The data comprise the amount of electricity, natural gas and water used during processing. The climate change value of the processing step is calculated by considering the amount of natural gas that is combusted during processing (Aubé, 2001) and the amount of electricity that is used. To calculate the amount of greenhouse gas emission, the amount of combusted natural gas at the processing factory are added to the amount of fossil fuels combusted at the electricity power plant (approximately $78 \%$ of all electricity sources in the Netherlands (Wernet et al., 2016)) and multiplied with the amount of greenhouse gas emission that occur by burning fossil fuels. Since the agricultural production of food products is the main contributor in terms of land use (Broekema \& Blonk, 2009), the processing step is expected to not contribute considerably to the land use value of the meat replacers. Therefore, this impact indicator is not included in the end product results. The water use value is calculated by considering the amount of water required to produce $1 \mathrm{~kg}$ of meat replacer. The fossil fuel depletion value of the processing step was calculated by considering the amount of natural gas and electricity used. As in the calculation of the climate change value, it is assumed that $78 \%$ of the electricity sources comprise fossil fuels (Wernet et al., 2016).

The nutritional and environmental data of all the ingredients and the references can be found in appendix $\mathrm{C}$, as well as the environmental data of the references.

\subsubsection{Assumptions about data}

This study assumes that the processing of ingredients into meat replacers takes place in the Netherlands. The environmental data of the ingredients and the references include the impact of agricultural production of the products in a certain country, the transport to the Netherlands and for some ingredients the conversion into specific ingredients. The origins of the included legumes are based on the most important countries that produce the legumes for processing in the Netherlands (Broekema \& Smale, 2011). The model can be applied to other countries by inserting corresponding data.

It is assumed that all the used legumes exist in the form of flour, protein concentrate and protein isolate and are used as ingredients in these forms. In reality, not all legumes may exist in these forms (Broekema \& Smale, 2011). Whereas nutritional data of all the included legumes in dry form are available, nutritional data of flour, protein concentrate and protein isolate are only available for soy. The nutritional value of the flours of the other legumes is assumed to be equal to that of dry legumes. The nutritional value of their protein concentrates and isolates are estimated using conversion factors 
that exist between the nutritional value of dry soy beans, soy protein concentrate and soy protein isolate. For chickpeas, kidney beans, lentils and wheat, only environmental data of their unprocessed form is available. For soy, peas and lupine, environmental data about flour and concentrate is available and for soy and peas environmental data about the protein isolate form is available. Based on soy, estimations of environmental data of flour, concentrate and isolate of chickpeas, kidney beans, lentils and wheat are made.

Environmental data about fortifications are not available. They are generally assumed to have a relatively high environmental impact, since it requires a lot of purification steps to obtain them (Broekema \& Smale, 2011). However, only a very small amount of fortification has to be added to achieve the required amount of the nutrient, so it is assumed that their contribution is not very high. That is why an estimation of the environmental impact values of the fortifications is made. For every environmental impact indicator, the largest value of all ingredients is taken and rounded up. These values are chosen as the environmental impact values of the fortifications. In this way, it is assumed that the fortifications have higher environmental impact values than all the other ingredients. To study the effect of changes in the environmental impact values of the fortifications, we carried out a sensitivity analysis on these values (Appendix E).

We only consider the nutritional composition of the meat replacer and did not consider the nutritional composition of the complete diet. The absorbability of zinc and non-heme iron are however dependent on the presence of certain components in the diet, which influences the required content of zinc and non-heme iron in the meat replacers. To investigate the effect of changes in the required contents, a sensitivity analysis is executed (Appendix E).

281 Based on the electricity, natural gas and water consumption from practice (Averink, 2015), the climate change, water use and fossil fuel depletion values for the meat replacers during processing are estimated. Data for specific processes or products are not available (Averink, 2015). Therefore, the environmental impact values of the processing phase are estimated from the total amount of electricity, natural gas and water consumed and by dividing these values by the total amount of produced products. Consequently, the environmental impact values during processing is assumed to be constant and not dependent on the ingredients that are used.

\subsection{Mathematical model}

The model uses the following indices, variables, and parameters:

\section{Indices}

$i \quad$ Index for ingredients, see Appendix C

$(i=1 \ldots 29)$

$j \quad$ Index for nutrients, see Appendix A

$(j=1 \ldots 13)$

$k \quad$ Index for references: $k=1$ for chicken and $k=2$ for beef

$(k=1 \ldots 2)$

$e \quad$ Index for environmental impact indicator:

$(e=c c, l u, w u, f d)$ 
$c c$ for climate change value $\left(\mathrm{kg} \mathrm{CO}_{2} \mathrm{eq} / \mathrm{kg}\right)$

lu for land use value $\left(\mathrm{m}^{2} / \mathrm{year} / \mathrm{kg}\right)$

$w u$ for water use value $\left(\mathrm{m}^{3} / \mathrm{kg}\right)$

fd for fossil fuel depletion $(\mathrm{MJ} / \mathrm{kg})$

\section{Variables}

$X_{i} \quad$ Amount of the ingredient $i$ in the meat replacer (\%)

$Z_{e} \quad$ Value of environmental impact indicator $e$

$(e=c c, l u, w u, f d)$

\section{Parameters}

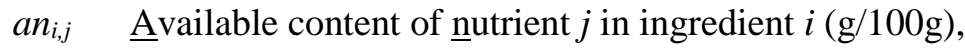

$r n_{j, k} \quad$ Required content of nutrient $j$ in the meat replacer based on reference product $k(\mathrm{~g} / 100 \mathrm{~g})$

$a w_{i} \quad$ Available water content of ingredient $i(\mathrm{~g} / 100 \mathrm{~g})$

$r w_{L B} \quad$ Lower bound of required water content in the meat replacer

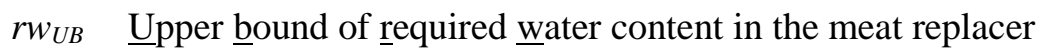

$c c_{i} \quad$ Climate change value $\left(\mathrm{kg} \mathrm{CO}_{2} \mathrm{eq} / \mathrm{kg}\right)$ of ingredient $i$

$l u_{i} \quad$ Land use value $\left(\mathrm{m}^{2} /\right.$ year $\left./ \mathrm{kg}\right)$ of ingredient $i$

$w u_{i} \quad \underline{\text { Water }}$ use value $\left(\mathrm{m}^{3} / \mathrm{kg}\right)$ of ingredient $i$

$f d_{i} \quad$ Fossil fuel depletion $(\mathrm{MJ} / \mathrm{kg})$ of ingredient $i$

294 The model contains four types of constraints: expressions for calculating environmental impact

295 indicators, nutritional constraints, technical constraints, scenario constraints.

\section{Environmental impact indicators}

298 ingredients:

$$
Z_{c c}=\sum_{i=1}^{29} c c_{i} X_{i}
$$

$$
Z_{l u}=\sum_{i=1}^{29} l u_{i} X_{i}
$$

$$
Z_{w u}=\sum_{i=1}^{29} w u_{i} X_{i}
$$

$$
Z_{f d}=\sum_{i=1}^{29} f d_{i} X_{i}
$$




\section{Nutritional constraints}

Nutritional constraints are based on the nutritional value of the references chicken $(k=1)$ and beef $(k=2)$. With $k$ as a reference, the amount of nutrient $j$ contributed by the ingredients $i$ should at least be equal to the amount of nutrient $j$ in that reference $\left(r n_{j, k}\right)$ :

$$
\sum_{i=1}^{29} a n_{i, j} X_{i} \geq r n_{j, k} \quad \text { for } j=1 \ldots 13
$$

\section{Technical constraints}

The total weight of the meat replacer should be 100 grams (Vivera, 2016):

$$
\sum_{i=1}^{29} 100 X_{i}=100
$$

Since the meat replacer should be a cohesive, consumable end product, the total water content should be between the lower bound $r w_{L B}\left(55 \mathrm{~g}\right.$ per $100 \mathrm{~g}$ ) and the upper bound $r w_{U B}(65 \mathrm{~g}$ per $100 \mathrm{~g}$ ) (RIVM, 2013):

$$
r w_{L B} \leq \sum_{i=1}^{29} a w_{i} X_{i} \leq r w_{U B}
$$

\section{Scenario constraints}

The four different scenarios (vegetarian, vegan, insect-based, fortification-free) are modeled by adding one of the following four scenario constraints.

- For the vegetarian meat replacer, no insects are allowed. Therefore, the amounts of meal worms $\left(X_{24}\right)$ and super worms $\left(X_{25}\right)$ should be zero:

$$
X_{i}=0 \quad \text { for } i \in\{24,25\}
$$

- In the vegan meat replacer, no animal-based product and no insects are allowed. Therefore, the amounts of eggs $\left(X_{22}\right)$, cheese $\left(X_{23}\right)$, meal worms $\left(X_{24}\right)$ and super worms $\left(X_{25}\right)$ should be zero:

$$
X_{i}=0 \quad \text { for } i \in\{22,23,24,25\}
$$

- The main ingredient of the insect-based meat replacer should be insects. Therefore, the summed contents of meal worms $\left(X_{24}\right)$ and super worms $\left(X_{25}\right)$ should be at least 15\% (Damhert, 2016):

$$
X_{24}+X_{25} \geq 0.15
$$

- In the fortification-free meat replacer, no iron- $\left(X_{27}\right)$, vitamin B12- $\left(X_{28}\right)$, or zinc $\left(X_{29}\right)$ fortifications are allowed:

$$
X_{i}=0 \quad \text { for } i \in\{27,28,29\}
$$




\subsection{Approach to multi-objective problem}

Finding the meat replacer with the lowest environmental impact is a multi-objective problem since it requires minimizing four conflicting environmental impact indicators $Z_{e}$ at the same time: climate change, land use, water use and fossil fuel depletion. These indicators have different units and scales, so they cannot simply be summed and minimized together. In order to explore the problem, first the indicators $Z_{e}(e=c c, l u, w u, f d)$ are minimized separately. These minimizations provide the lowest (i.e. best) possible value of each indicator $Z_{e}$, which is referred to as $Z_{e}{ }^{*}$. The $Z_{e}$ values resulting from the four individual minimizations are put in so-called payoff matrices. In the (fictitious) payoff matrix of Table 2, minimizing environment impact indicator $Z_{l u}$ leads to a solution in which $Z_{c c}=0.7, Z_{l u}=3$, $Z_{w u}=0.04$, and $Z_{f d}=19$. When minimizing $Z_{c c}$ to $Z_{f d}$ individually, the obtained values of $Z_{l u}$ range from 3 (when $Z_{l u}$ is minimized) to 8 (when $Z_{f d}$ is minimized). The highest (i.e. worst) value of $Z_{e}$ in the payoff matrix is indicated as $\underline{Z}_{e}$, so $Z_{l u}{ }^{*}=3$ and $\underline{Z}_{l u}=8$. In the payoff matrix the lowest (best) value of $Z_{e}$ is indicated with "**" and the highest (worst) value is underlined.

Table 2. Fictitious example of a payoff matrix (left) and the resulting normalized impact values de $(e=c c, l u$, wu, fd $)(r i g h t)$.

\begin{tabular}{|c|c|c|c|c|c|c|c|c|c|}
\hline \multicolumn{6}{|c|}{ Payoff matrix } & \multicolumn{4}{|c|}{ Normalization } \\
\hline & & \multicolumn{4}{|c|}{ Observed environmental indicator } & \multicolumn{4}{|c|}{ Normalized environmental indicator } \\
\hline & & $Z_{c c}$ & $Z_{l u}$ & $Z_{w u}$ & $Z_{f d}$ & $\boldsymbol{d}_{c c}$ & $d_{l u}$ & $d_{w u}$ & $d_{f d}$ \\
\hline \multirow{4}{*}{ 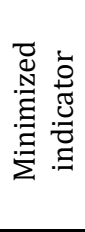 } & $Z_{c c}$ & $0.5^{*}$ & 5 & $\underline{0.07}$ & $\underline{20}$ & $0^{*}$ & 0.4 & 1 & $\underline{1}$ \\
\hline & $Z_{l u}$ & 0.7 & $3^{*}$ & 0.04 & 19 & 0.2 & $0^{*}$ & 0.5 & 0.9 \\
\hline & $Z_{w u}$ & $\underline{1.5}$ & 7 & $0.01^{*}$ & 11 & $\underline{1}$ & 0.8 & $0^{*}$ & 0.1 \\
\hline & $Z_{f d}$ & 1.2 & $\underline{8}$ & 0.04 & $10^{*}$ & 0.7 & $\underline{1}$ & 0.5 & $0^{*}$ \\
\hline
\end{tabular}

Because the four environmental impact indicators have different units and values, the $Z_{e}$ are normalized to values $d_{e}$ in a 0-1 interval (Romero \& Rehman, 2003), in which 0 represents the lowest value and 1 represents the highest value:

$$
d_{e}=\frac{Z_{e}-Z_{e}^{*}}{\underline{Z}_{e}-Z_{e}^{*}} \text { for } e=c c, l u, w u, f d
$$

The right-hand side of Table 2 shows the normalized environmental impact indicators $d_{e}$. For example, $Z_{l u}=5$ (in the first row of the left-hand side) is transformed to $d_{l u}=\left(Z_{l u}-Z_{l u}{ }^{*}\right) /\left(\underline{Z}_{l u}-Z_{l u}{ }^{*}\right)=(5-3) /(8-$ $3)=0.4$.

Then, the four environmental impact indicators are minimized together by minimizing the $d_{e}$ in two ways:

- minsum objective: minimize $\left\{d_{c c}+d_{l u}+d_{w u}+d_{f d}\right\}$

- $\operatorname{minmax}$ objective: minimize $\left[\operatorname{maximum}\left\{d_{c c} ; d_{l u} ; d_{w u} ; d_{f d}\right\}\right]$ 
358 The minsum objective generates the solution (i.e. the composition of the meat replacer) in which the 359 sum of the normalized impact indicators $d_{e}$ is as low as possible. It is, however, possible that the 360 minsum solution is very unbalanced, i.e. the values of the individual normalized impact indicators are 361 very different (for example: one value is very large and others are very small). In contrast, the minmax

362 objective generates the solution in which the largest among the normalized impact indicators is as 363 small as possible, thus providing a solution that is as balanced as possible (Romero, 2001). 


\section{Results}

366

367

368

369

370

371

372

373

374

375

376

377

378

379

380

381

382

The model was used to compose vegetarian, vegan, insect-based and fortification-free replacers for chicken and beef. This section provides the ingredient results and end product results (as illustrated in Figure 1) of the composed chicken replacers and beef replacers. Their environmental impact values are compared with those of chicken and beef.

\subsection{Ingredient results}

\subsubsection{Ranges of the environmental impact indicators}

Minimizing the four individual environmental impact indicators $Z_{e}$ for the four types of meat replacers yields the payoff matrices (see Appendix D) from which the ranges of the individual impact indicators are observed (see Table 3). The payoff matrices for the vegetarian and the vegan chicken replacer are identical, because the optimal solutions are the same. This also is the case for the vegetarian and vegan beef replacer. It is not possible to compose a fortification-free beef replacer: the problem is infeasible when no fortifications are allowed.

Table 3. Observed ranges of the environmental impact indicators $Z_{e}$ for the feasible meat replacers, with $e=c c$ for climate change ( $\mathrm{kg} \mathrm{CO} 2 \mathrm{eq} / \mathrm{kg}$ ), $e=$ lu for land use ( $\mathrm{m} 2 / \mathrm{year} / \mathrm{kg}$ ), $e=$ wu for water use ( $\mathrm{m} 3 / \mathrm{kg}), e=f d$ for fossil fuel depletion $(M J / k g)$. The $Z_{e}{ }^{*}$ indicate the best (lowest) values of each indicator, the $\underline{Z}_{e}$ indicate the worst (highest) values of each indicator.

\begin{tabular}{|c|c|c|c|c|c|c|c|c|c|c|}
\hline & \multicolumn{6}{|c|}{ Chicken replacers } & \multicolumn{4}{|c|}{ Beef replacers } \\
\hline & \multicolumn{2}{|c|}{ Vegetarian/Vegan } & \multicolumn{2}{|c|}{ Insect-based } & \multicolumn{2}{|c|}{ Fortification-free } & \multicolumn{2}{|c|}{ Vegetarian/Vegan } & \multicolumn{2}{|c|}{ Insect-based } \\
\hline & $Z_{e}^{*}$ & $\underline{Z}_{e}$ & $Z_{e}^{*}$ & $\underline{Z}_{e}$ & $Z_{e}{ }^{*}$ & $\underline{Z}_{e}$ & $Z_{e}^{*}$ & $\underline{Z}_{e}$ & $Z_{e}^{*}$ & $\underline{Z}_{e}$ \\
\hline$e=c c$ & 0.62 & 1.35 & 0.95 & 2.71 & 1.41 & 2.71 & 0.59 & 1.31 & 0.91 & 2.70 \\
\hline$e=l u$ & 2.64 & 6.51 & 2.84 & 4.81 & 3.43 & 4.81 & 2.52 & 6.32 & 2.69 & 4.65 \\
\hline$e=w u$ & 0.017 & 0.069 & 0.007 & 0.068 & 0.007 & 0.115 & 0.019 & 0.070 & 0.007 & 0.069 \\
\hline$e=f d$ & 7.28 & 15.78 & 11.14 & 34.10 & 8.96 & 34.10 & 6.78 & 15.27 & 10.63 & 34.05 \\
\hline
\end{tabular}

\subsubsection{Results of minsum and minmax optimisations}

Figure 2 and Figure 3 show the optimal compositions $X_{i}$ of the chicken and beef meat replacers, respectively, for the minsum and minmax objectives. The meat replacers consist mainly of water and soy protein concentrate. The water is needed to ensure that the water content is between 55 and $65 \%$.

Soy appears to be a suitable replacer for meat, since it is selected to be the main ingredient for all meat replacers. This is assumingly because of its protein quality, which is comparable with that of meat (Asgar et al., 2010). 

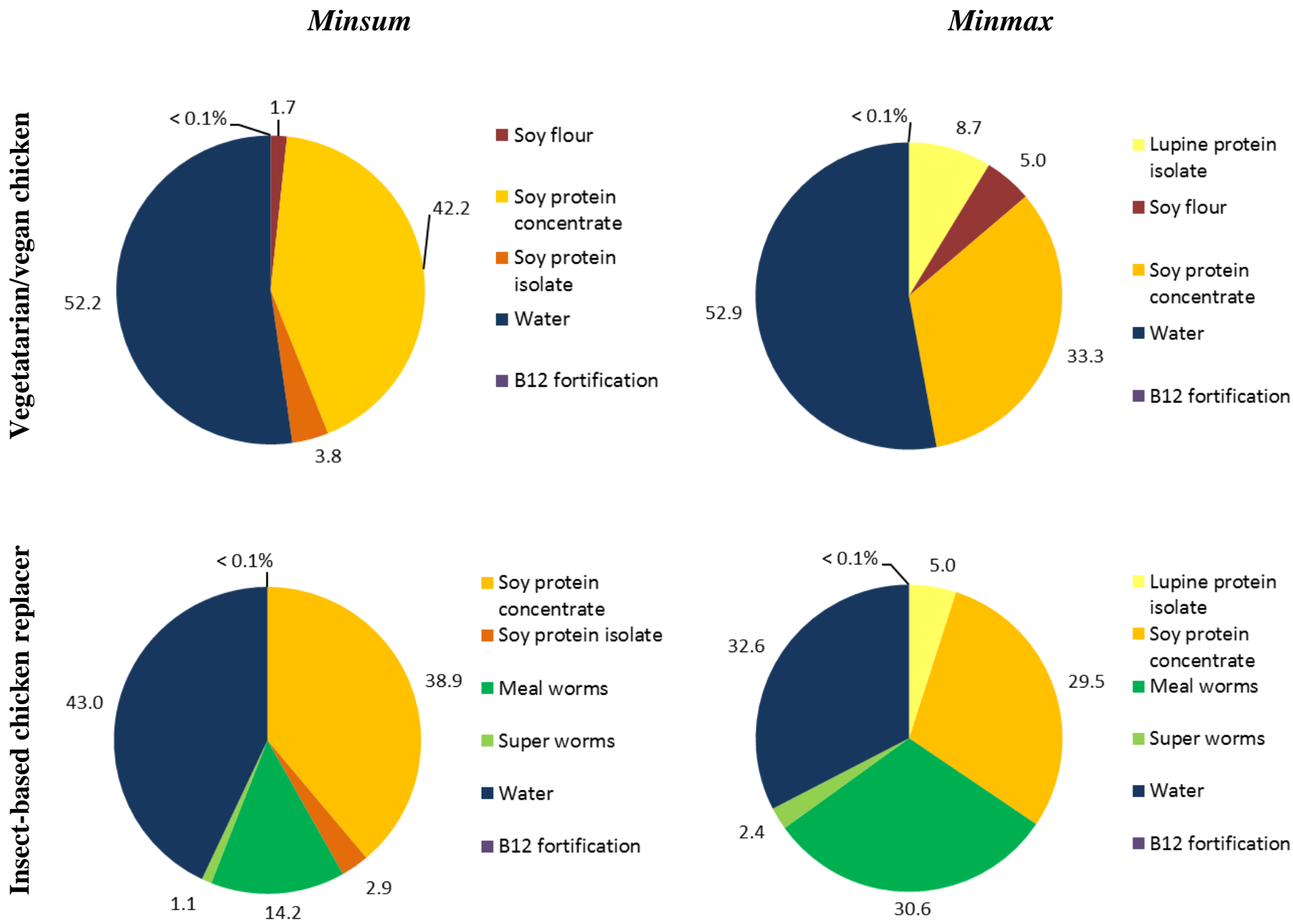

Meal worms

Super worms

- Water

B12 fortification

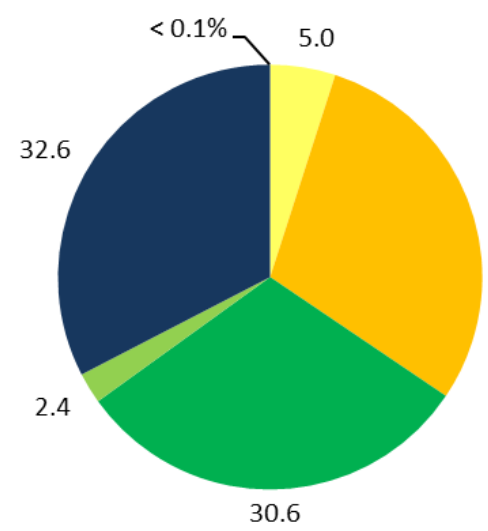

\section{Lupine protein isolate \\ Soy protein \\ concentrate \\ Super worms}

$29.5 \square$ Meal worms

- Water

- B12 fortification

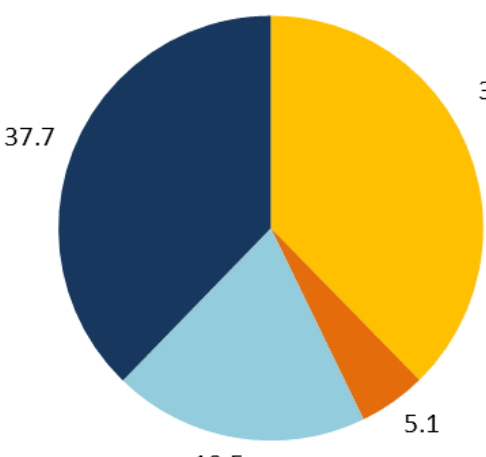

Soy protein
concentrate

37.7

- Soy protein isolate

Eggs

- Water

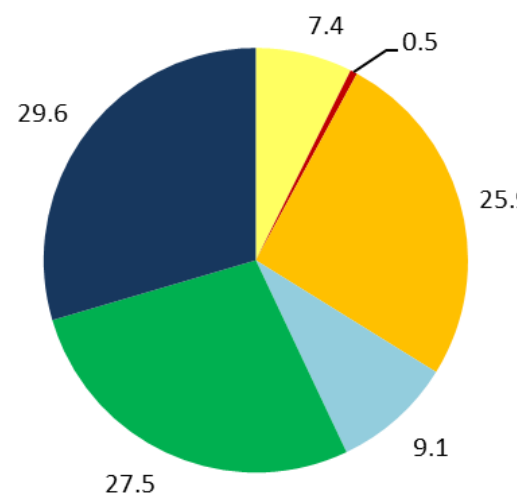

Lupine protein

isolate

- Soy flour

Soy protein

concentrate

Eggs

Meal worms

- Water

19.5

391 Figure 2. Composition of the vegetarian/vegan, insect-based and fortification-free chicken replacers for minsum (left) and minmax (right). Vitamin B12 fortification is present in very low quantities; the amounts are specified in Appendix G. 

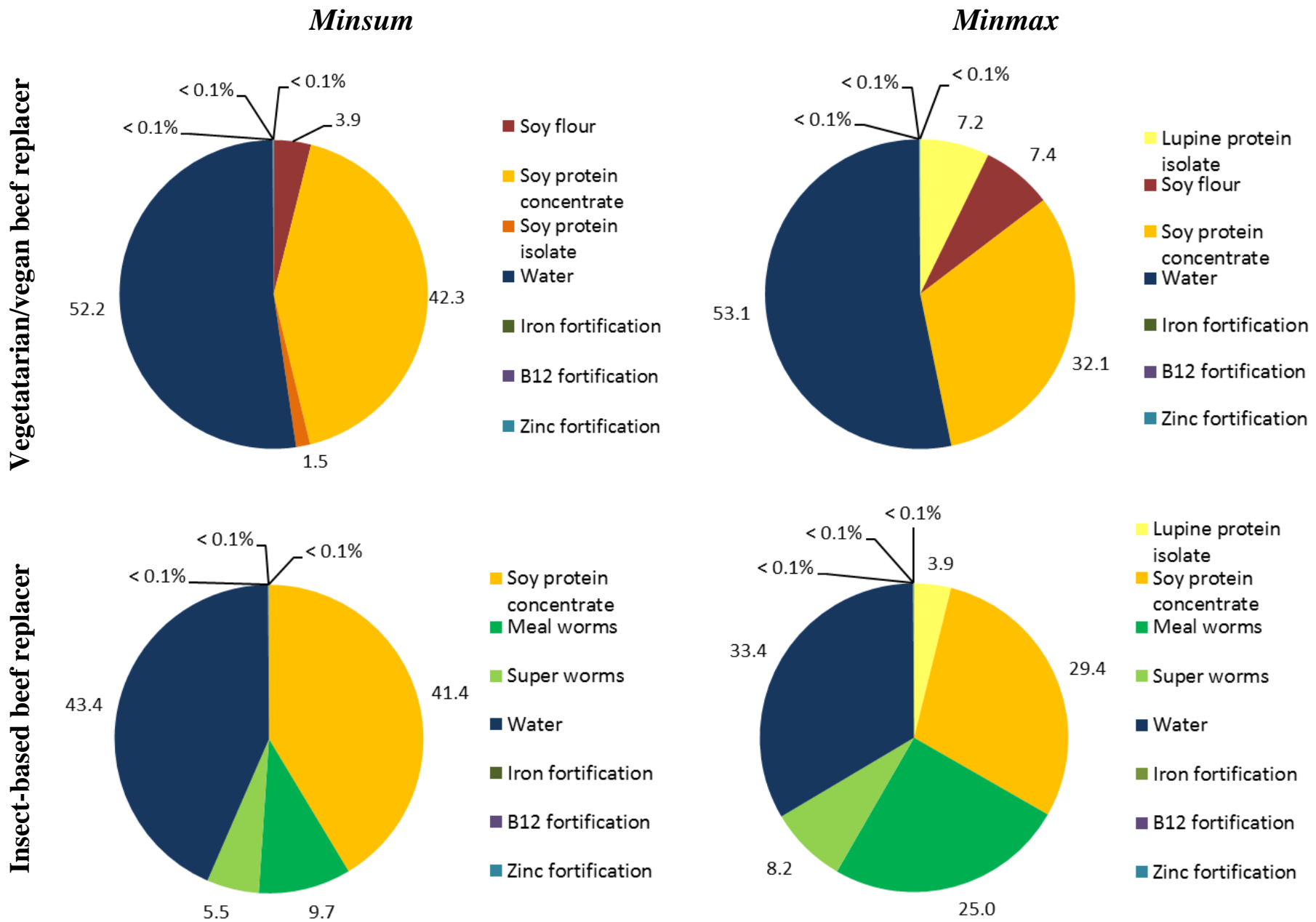

Figure 3. Composition of the vegetarian/vegan and insect-based beef replacer for minsum (left) and minmax (right).

Fortifications are present in very low quantities; their amounts are specified in Appendix G.

395 The vegetarian meat replacers and the insect-based meat replacers contain no animal-based products, although they are allowed. Based on the modelled results, it is more favorable to add fortifications than to add animal-based products to achieve the required amount of iron, vitamin B12 and zinc. The chicken replacers contain vitamin B12 fortification, but no fortifications for iron and zinc: sufficient amounts of these nutrients are provided through the other ingredients. In the beef replacers, iron-, vitamin B12- and zinc fortifications are necessary to meet the corresponding required amounts. In the fortification-free chicken replacer, eggs are used to obtain the required amount of vitamin B12.

402 The insect-based meat replacers have to contain at least $15 \%$ meal worms and/or super worms. The 403 meal worms are preferred over the super worms because they have a slightly better nutritional value.

404 For the minsum objectives, the amounts of insects are almost at their minimum allowed level because of their high fossil fuel depletion values. For the minmax objectives, the insect amounts are remarkably higher because of their low water use values, which are minimized in this objective. The

407 fortification-free chicken replacer also contains a considerable amount of meal worms for the minmax 408 objective, although they are not mandatory in this meat replacer. They are preferred over eggs,

409 because their water use is much smaller while they also contain vitamin B12. 
Table 4 shows the values of the environmental impact indicators $Z_{e}$, and the normalized environmental impact indicators $d_{e}$ for all meat replacers. In every minsum solution, water use $\left(d_{w u}\right)$ has the highest value among the $d_{e}$, and climate change $\left(d_{c c}\right)$ and land use $\left(d_{l u}\right)$ have very low values. The minsum solutions are thus relatively unbalanced. Minimizing the maximum among the $d_{e}$ decreases $d_{w u}$ at the cost of increasing $d_{c c}+d_{l u}+d_{f d}$. As a result, the minmax solutions are more balanced than the minsum solutions.

Table 4. Environmental impact indicators $Z_{e}$ and normalized environmental impact indicators de for all meat replacers, with $e=c c$ for climate change ( $\mathrm{kg}$ CO2 eq $/ \mathrm{kg}), e=l u$ for land use (m2/year $/ \mathrm{kg}), e=$ wu for water use $(\mathrm{m} 3 / \mathrm{kg}), e=$ fd for fossil fuel depletion $(\mathrm{MJ} / \mathrm{kg})$.

\begin{tabular}{|c|c|c|c|c|c|c|c|c|c|c|}
\hline & \multicolumn{6}{|c|}{ Chicken replacers } & \multicolumn{4}{|c|}{ Beef replacers } \\
\hline & \multicolumn{2}{|c|}{ Vegetarian/Vegan } & \multicolumn{2}{|c|}{ Insect-based } & \multicolumn{2}{|c|}{ Fortification-free } & \multicolumn{2}{|c|}{ Vegetarian/Vegan } & \multicolumn{2}{|c|}{ Insect-based } \\
\hline & minsum & $\operatorname{minmax}$ & minsum & $\operatorname{minmax}$ & minsum & $\operatorname{minmax}$ & minsum & $\operatorname{minmax}$ & minsum & $\operatorname{minmax}$ \\
\hline$Z_{c c}$ & 0.62 & 0.73 & 0.95 & 1.39 & 1.42 & 1.68 & 0.59 & 0.7 & 0.91 & 1.37 \\
\hline$Z_{l u}$ & 2.64 & 3.32 & 2.84 & 3.48 & 3.43 & 3.96 & 2.53 & 3.15 & 2.7 & 3.33 \\
\hline$Z_{w u}$ & 0.040 & 0.034 & 0.035 & 0.027 & 0.083 & 0.047 & 0.040 & 0.035 & 0.036 & 0.027 \\
\hline$Z_{f d}$ & 9.32 & 10.06 & 13.37 & 18.55 & 11.36 & 18.25 & 8.81 & 9.52 & 12.93 & 18.25 \\
\hline$d_{c c}$ & 0.01 & 0.15 & 0.00 & 0.25 & 0.00 & 0.21 & 0.00 & 0.15 & 0.00 & 0.26 \\
\hline$d_{l u}$ & 0.00 & 0.18 & 0.00 & 0.32 & 0.00 & 0.37 & 0.00 & 0.17 & 0.00 & 0.33 \\
\hline$d_{w u}$ & 0.44 & 0.33 & 0.46 & 0.32 & 0.70 & 0.37 & 0.42 & 0.32 & 0.46 & 0.33 \\
\hline$d_{f d}$ & 0.24 & 0.33 & 0.10 & 0.32 & 0.10 & 0.37 & 0.24 & 0.32 & 0.10 & 0.33 \\
\hline
\end{tabular}

420

421

422

Figure 4 shows the environmental impact values of the meat replacers, and the contributions of their ingredients. They are compared with the environmental impact values of chicken and beef. For climate change, land use and fossil fuel depletion, the vegetarian/vegan meat replacers have the lowest impact for both minimizations and for both references. For water use, the insect-based meat replacers have the lowest impact for both minimizations and references. For climate change and land use, the meat replacers have lower impact values than their references. For water use, the vegetarian/vegan and insect-based meat replacers have lower impact values than their references. Only the fortification-free chicken replacer in the minsum optimization has higher water use value than chicken, which is mainly due to the high water use value of eggs. In the minmax optimization, however, the water use of the fortification-free chicken replacer is lower than that of chicken, because of the low water use of meal worms. For fossil fuel depletion, the values of all meat replacers in the minsum optimization are lower than that of their references. In the minmax optimization, the fossil fuel depletion values of the insectbased and fortification-free chicken replacers are slightly higher than those of chicken, because of the high contribution of meal worms. Soy protein concentrate contributes greatly to all environmental impact values because of its high content in all meat replacers. The overall contributions of the iron-, vitamin B12- and zinc- fortifications are very low, because only small amounts of them are needed to achieve the required amount of these nutrients. The environmental impact values for beef replacers are 
437 smaller than those for chicken replacers, because the protein content of beef is slightly lower than that

438 of chicken. As the required protein amount is a binding constraint it has a direct effect on the solution.

\section{Minsum}
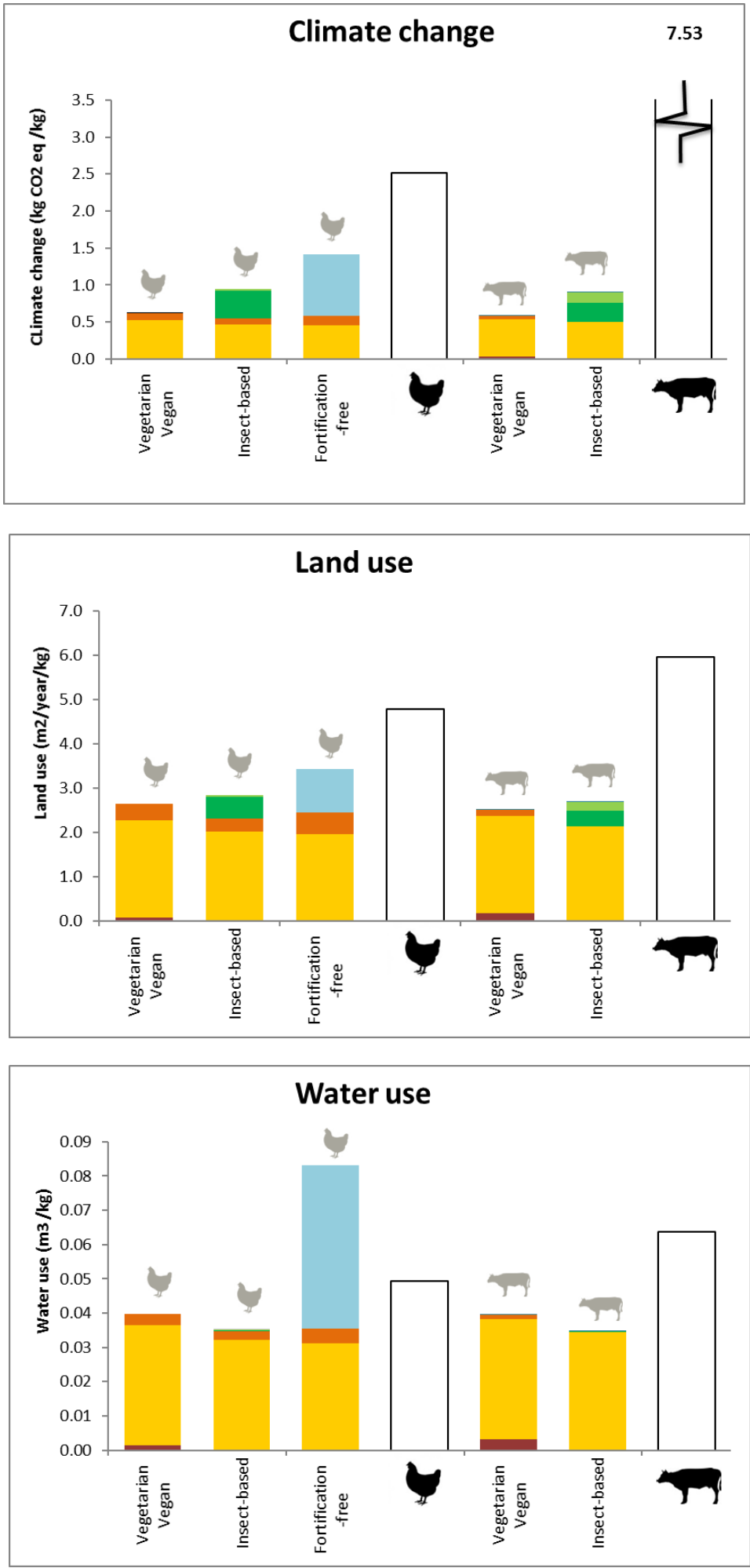

Minmax

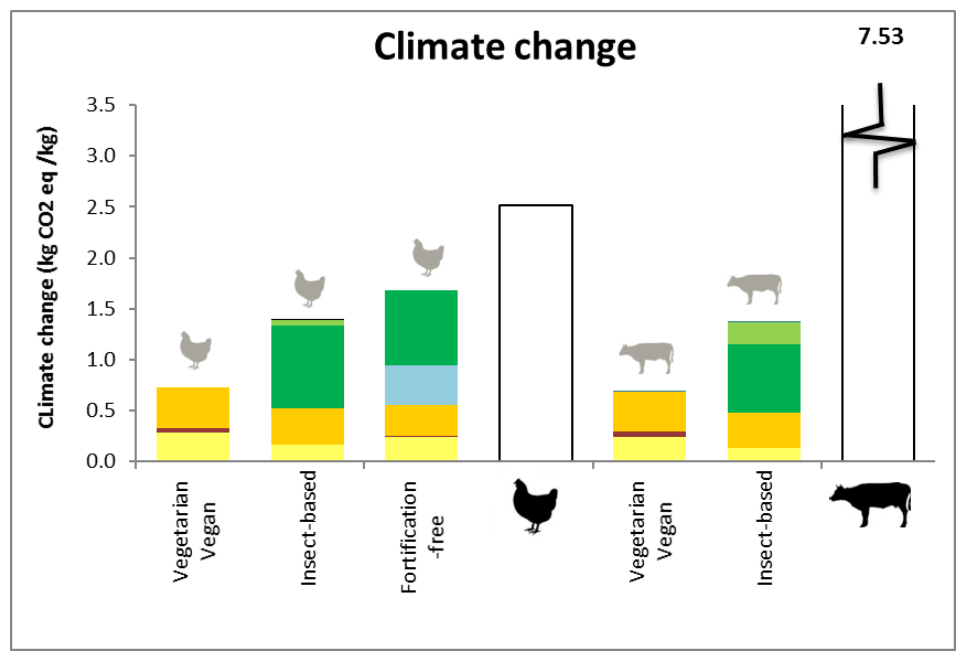

Land use
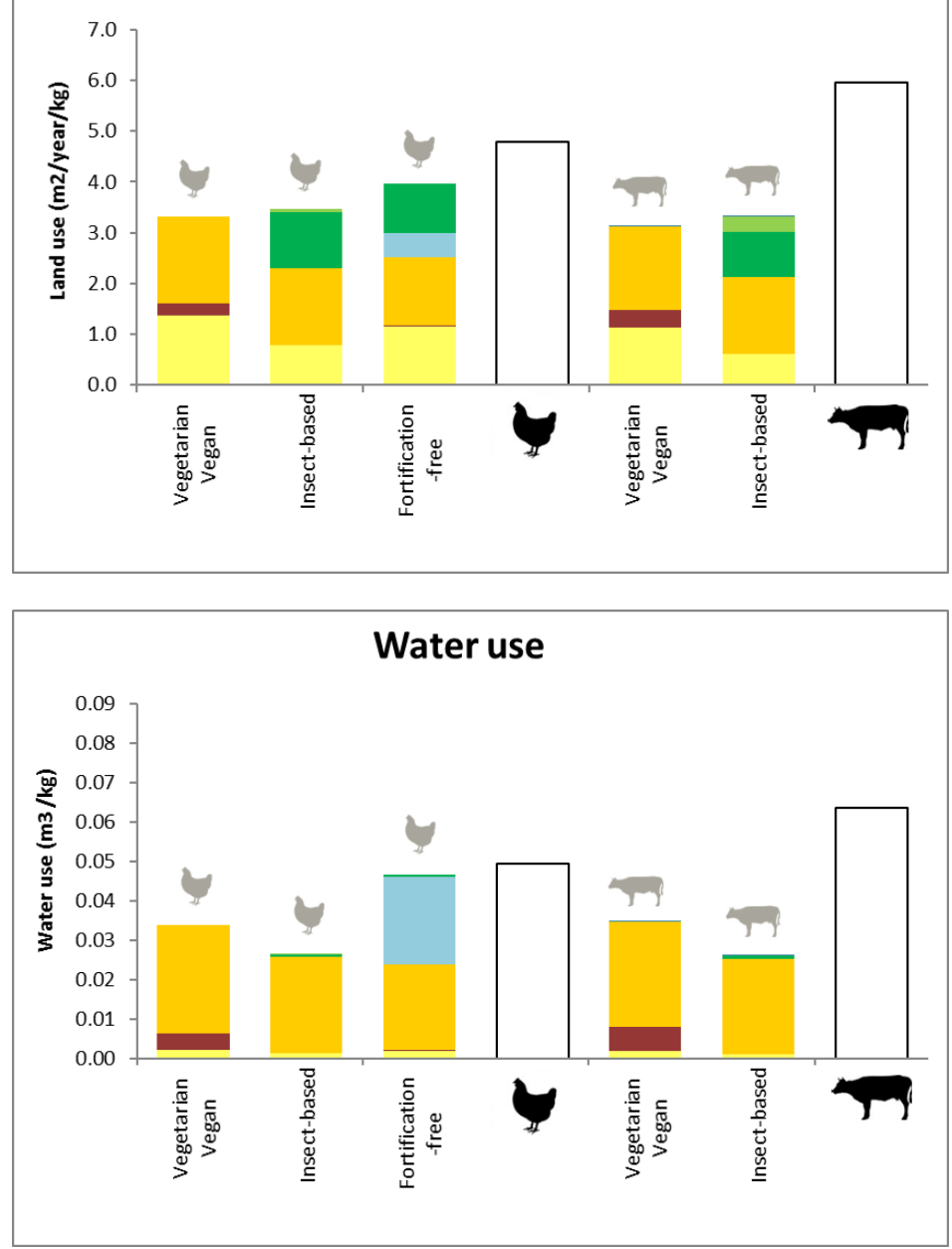

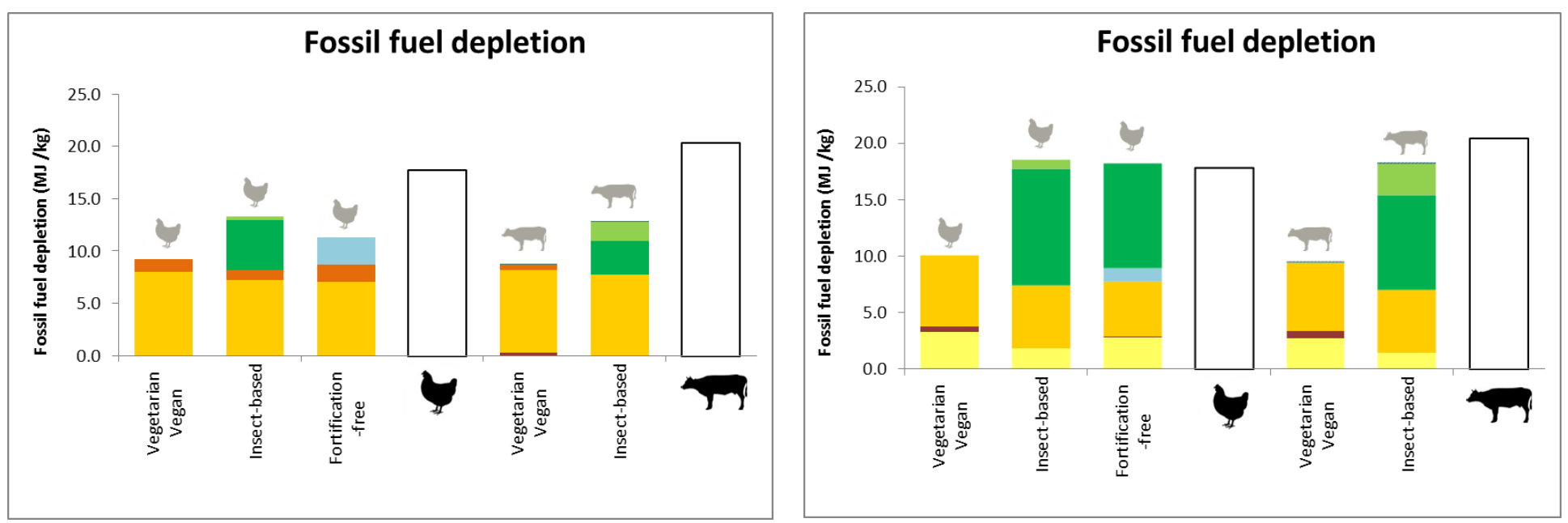

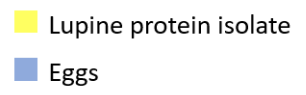

Eggs

Iron fortification

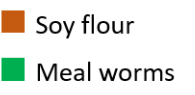

B12 fortific

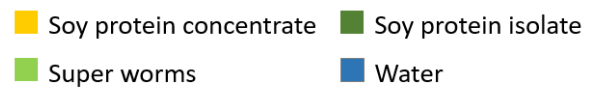

Zinc fortification

$440 \quad$ Figure 4. Environmental impact values of the meat replacers, specified per ingredient, compared with the environmental 441 impact values of chicken and beef, for the minsum optimization (left) and the minmax optimization (right). The grey

442 pictograms above the bars indicate which reference is used. The climate change value of beef $(7.53 \mathrm{~kg} C O 2 \mathrm{eq} / \mathrm{kg}) \mathrm{does}$ not

443 fit on the scale. A black-and-white version of this figure can be found in Appendix F.

\section{$444 \quad 3.2$ End product results}

445 Figure 5 visualizes the total climate change, water use and fossil fuel depletion values of the meat

446 replacers as end products. The contribution of the ingredients (as given in the ingredient results) and

447 the processing step are represented separately. For climate change, the processing phase has a

448 considerable contribution compared to the contribution of the ingredients: on average $26 \%$ for the

449 chicken replacers and $30 \%$ for the beef replacers. However, as in the ingredient results, the climate

450 change values of the replacers are all smaller than the climate change value of their reference. For

451 water use, the processing phase has a relatively low contribution: on average $14 \%$ of the total water

452 use value for the chicken replacers and $16 \%$ for the beef replacers. As in the ingredient results, the

453 water use of the fortification-free chicken replacer exceeds the water use of chicken in the minsum

454 solutions. In the minmax solutions, the contribution of the processing step makes the water use of the

455 fortification-free chicken replacer exceed the water use of chicken. The water use values of the beef

456 replacers are still lower than the value of beef for both optimizations, as in the ingredient results. For

457 fossil fuel depletion, the processing step contributes on average $36 \%$ for the chicken replacers and

$45838 \%$ for the beef replacers. By adding the processing step, the fossil fuel depletion value of the insect-

459 based and fortification-free chicken replacer for the minsum optimization exceed the value of chicken.

460 As in the ingredient results, the fossil fuel depletion of the insect-based and fortification-free chicken

461 replacers for the minmax optimization exceed the value of chicken. Also the fossil fuel depletion value

462 of the insect-based beef replacer for the minmax optimization exceeds the value of beef by adding the

463 processing step. 
Minsum
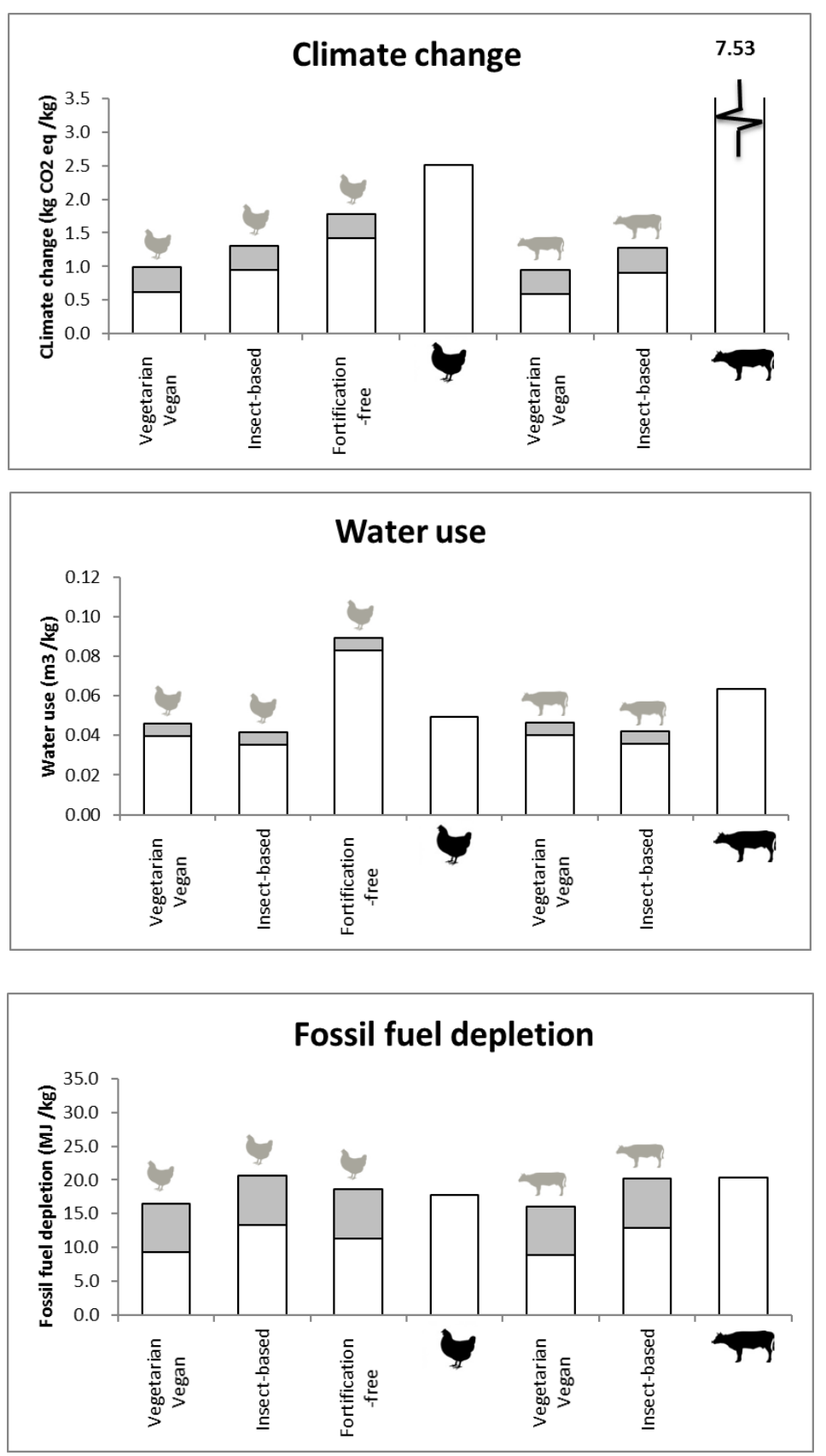

Minmax
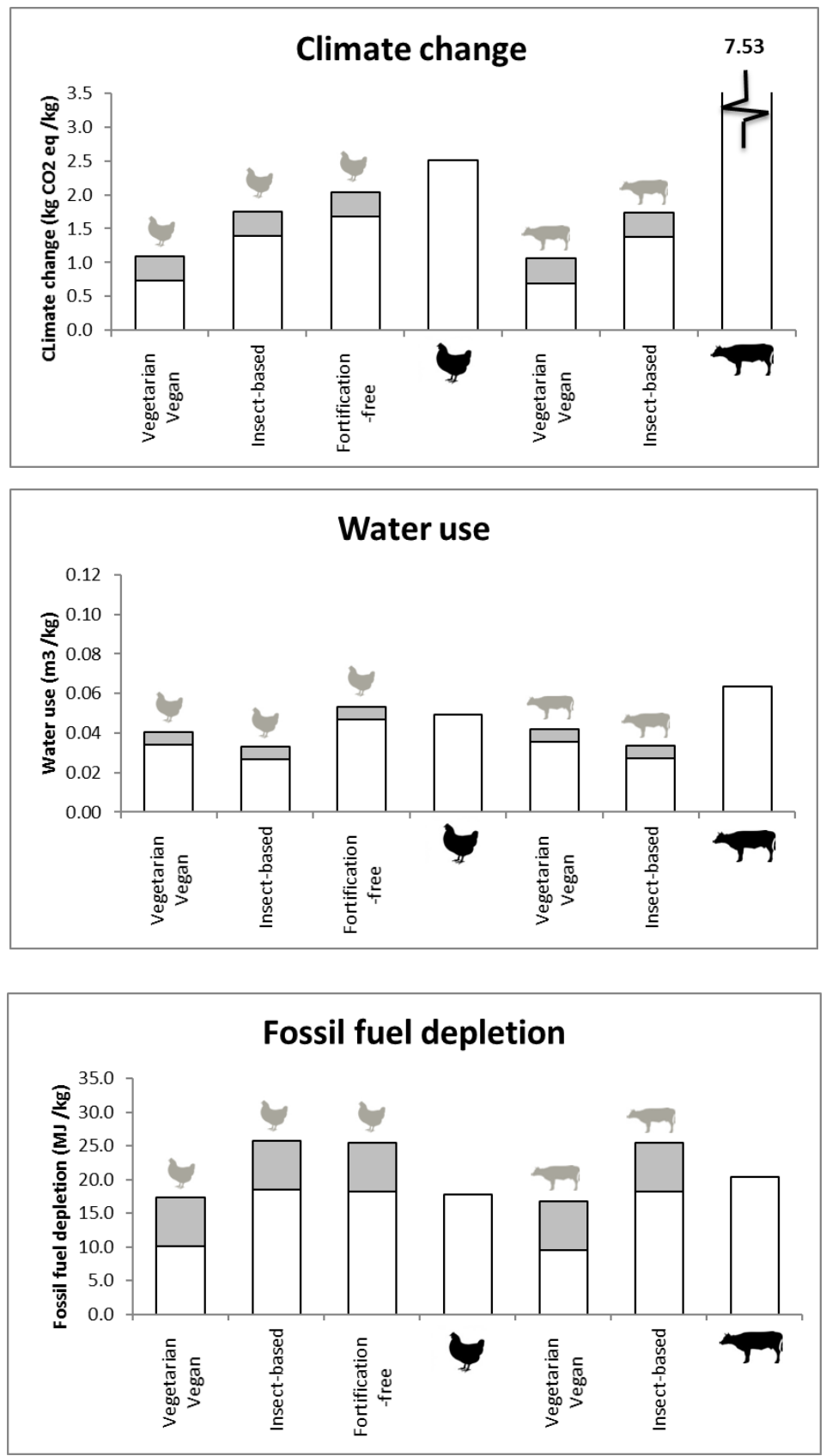

$\square$ Ingredients $\square$ Processing

464

465

466

467
Figure 5. End product results: climate change, water use and fossil fuel depletion of the meat replacers compared with the environmental impact values of chicken and beef, for the minsum optimization (left) and minmax optimization (right). The grey pictograms above the bars indicate which reference is used. The contribution of the ingredients (white) and processing (grey) are given separately. 


\section{Discussion}

469 The need for more sustainable food choices is obvious, as current consumption and production

470 patterns threaten the environment. Replacing meat, as one of the main contributors to these threats, can

471 lower the burden and has been investigated by a variety of researchers (Hallström et al., 2015;

472 MacDiarmid et al., 2012; Wilson et al., 2013; Tyszler et al., 2014; Temme et al., 2013). However,

473 meat also provides important nutrients in the diet and thus needs to be substituted by other products

474 that can compensate for the reduction in meat. The results of this study show that it is possible to

475 compose meat replacers with a lower environmental impact and an equivalent nutritional contribution

476 with regards to energy, iron, zinc, vitamin B12 and the essential amino acids. One of the main

477 advantages of such a meat replacer is that it can be used as a direct substitute and does not require

478 further dietary changes, facilitating the shift to more sustainable food consumption (Schösler et al.

479 2012). Previous research has focused more on the comparison of different dietary scenarios (Meier and

480 Christen, 2012; Berners-Lee et al., 2012; van Dooren et al., 2014), the design of alternative diets and

481 meals (MacDiarmid et al. 2012; Wilson et al., 2012, Tyszler et al., 2016) or the replacement of

482 individual products within such scenarios (Tyszler et al., 2014; Temme et al., 2013; Davis et al.,

483 2010). The diet is generally viewed as the best unit to evaluate nutritional choice and adequacy (Van

484 Kernebeek et al., 2014). However, former research showed that a reduction of meat often leads to

485 significant changes within the diet (Schösler et al., 2012). This could be avoided by designing products

486 that are equivalent and therefore instant replacements.

487 Given the list of ingredients, nutritional equivalence was feasible for all scenarios with the exception

488 of a fortification free beef replacer, due to the amount of iron, vitamin B12 and zinc present in beef.

489 For the feasible scenarios, the results of this study indicate that the vegan replacements have the

490 largest potential to reduce environmental impact in terms of climate change and land use, with

491 reduction of up to $87 \%$ and $58 \%$, respectively. This is consistent with previous studies investigating

492 different dietary scenarios (Hallström et al., 2015; van Dooren et al., 2014) and studies comparing

493 meat with meat replacers (Smetana et al., 2015; Zhu \& van Ierland, 2004). Adding to previous work,

494 this study further concluded that this also holds for fossil fuel depletion (with reductions up to $21 \%$ ),

495 while with regards to water use the best results are obtained for the insect-based replacer (with

496 reductions up to $47 \%$ ), due to the small water requirements of super worms and meal worms. The

497 results show that it is not always favorable to replace chicken and/or beef due to high fossil fuel

498 depletion values of the replacements. For the insect-based chicken replacer for example, the fossil fuel

499 depletion value is $45 \%$ higher than the value of chicken (for the minmax optimization). This can be

500 mainly attributed to the fact that the difference between the replacers and their references in the

501 ingredient results is already small and the processing step adds considerably to the fossil fuel value.

502 From the results we can see a shifting of the burden between environmental impact categories

503 depending on the ingredients used. Minimizing the environmental impact of one category can thus 
lead to negative effects with respect to another, as trade-offs exist between the different environmental impact categories. This also applies to the shift from meat to plant based alternatives when incorporating the processing step in the results. Further investigation of the processing step could help to gain insights into potential areas of improvement, making this step more efficient and environmentally friendly. In this context however, it should also be noted that the replacers are already preprocessed and thus might require less energy and preparation than meat at the household stage, where energy use is often less efficient (Sonesson et al., 2005). Future research could try to incorporate environmental impacts of the household stage to provide a more comprehensive analysis.

With regards to the ingredients, the findings of this research identify soy as a key ingredient when trying to mimic the nutrient profile of meat, due to its amino acid contribution and its low environmental impact. More recently, the environmental impact of soy has, however, come under scrutiny and been subject to debate and substantial criticism within the research community due to its link to climate change and deforestation (Costa et al., 2007; Arima et al., 2011). Research shows that linkages exist between the production of soy and deforestation levels in major forest regions within Brazil and Argentina, such as the Amazon rainforest and the Argentinian Dry Chaco (Lima et al., 2011; Gasparri et al., 2013). This can have major implications for the environmental impact of soy and indirectly also of meat, with soy being one of the main feed ingredients in today's livestock systems and most of the soy production being triggered by the demand for feed (Billen et al., 2014; Viglizzo et al., 2011). It should thus be noted that there are concerns regarding the environmental impact of soy, with significant differences between production systems and/or regions (Da Silva et al., 2010; Castanheira and Freire, 2013). However, as the conversion of plant-based to animal protein is inefficient (Aiking, 2011), a shift from meat to soy-based products, provided this leads to a lower consumption of meat, is unlikely to add further pressure (see Appendix $\mathrm{H}$ for a more extensive overview/discussion)

While this study provides valuable insights, adding to the scientific research on dietary intake and environmental impacts, it should be noted that there are some underlying assumptions and limitations that require further attention. One of the main limitations of this study, is the assumption that the ingredients of the model are combined and processed into a meat replacer without taking into account structure and taste. In practice, functional ingredients have to be added to obtain a good structure and taste (Averink, 2015). These ingredients could increase the environmental impact of the meat replacer substantially: the functional ingredient chicken egg protein, for example, has very high values for climate change (16.59 $\mathrm{kg} \mathrm{CO} 2 \mathrm{eq} / \mathrm{kg})$, land use $\left(31.02 \mathrm{~m}^{2} / \mathrm{y} / \mathrm{kg}\right.$ ) and fossil fuel depletion (13.04 MJ/kg) (Broekema \& Blonk, 2009). To get more information about the use of functional ingredients and their environmental impact, more research in collaboration with producers of meat replacers could be of interest. 
539 Furthermore, with regards to nutritional equivalency, this study only considers the most important

540 nutrients present in meat. Therefore, not taking into account additional nutrients provided by the plant-

541 based ingredients or other factors that could for instance affect absorption rates. The absorbabilities of

542 non-heme iron and zinc, for example, depend on the presence of specific components in the diet.

543 Phytates, for example, inhibit the absorption of zinc and non-heme iron, which means that more of

544 these nutrients should be consumed when phytates are present in the diet (FAO/WHO, 2002; Monsen

545 et al., 1978). Legumes and grains are the main sources of phytates, including soy beans (Schlemmer et

546 al., 2009). Since soy represents a large part of the meat replacers, the absorbabilities of iron and zinc

547 could be hindered. A sensitivity analysis (Appendix E) shows that the optimal solutions are not

548 sensitive for changes in the value of the required contents of iron and zinc in the chicken replacers.

549 However, for the beef replacers the optimal solutions are very sensitive for changes in the required

550 contents of zinc and iron. It should be investigated how components like phytates affect the required

551 content of non-heme iron and zinc in the replacement products and how this can be integrated it in the

552 model. Another suggestion is to examine the replacers within a broader dietary setting to better

553 understand the effect of nutrient contributions outside the scope of the reference nutrients.

554 This study relies on a limited number of LCA studies for the environmental data of the ingredients.

555 The consulted studies, however, have the same framework, being the applied (geographical)

556 boundaries, functional unit and allocation method. Since the framework of existing LCA studies often

557 deviate, including data from additional studies would entail more uncertainty. There is thus a need for

558 harmonization of LCA methods, since it facilitates the comparison of future studies (Margni \& Curran,

559 2012).

560 The model included a limited number of ingredients, which were selected based on their nutritional

561 value and based on recipes of a meat replacer producer (Averink, 2015). Certain forms of the

562 ingredients were selected, depending on their general application in industry and the availability and

563 quality of their data. For some ingredients, however, assumptions concerning their environmental

564 impact were made. Since environmental impact data of iron, zinc and vitamin B12 fortifications were

565 not available, we made an estimation of these data. A sensitivity analysis (Appendix E) however

566 shows that the model results are hardly sensitive to changes in the environmental impact values of the

567 fortifications. This study could be expanded by including more ingredients, provided that the

568 framework of the consulted LCA studies correspond. 


\section{Conclusion}

570 This study proposes a linear programming model in order to compose nutrient equivalent substitutes

571 for meat that can be used as direct replacements and lower the environmental impact of our diet. The

572 results suggest, that a shift from meat to plant-based products can lead to significant reductions in

573 terms of the environmental impact, without losing the nutritional benefits of meat. The vegan replacers

574 have the biggest potential to realize environmental impact reductions with regards to climate change,

575 land use and fossil fuel depletion. With respect to water use, the insect-based replacers show the most

576 promising reduction potential. The level of reduction further depends on the kind of meat that is

577 replaced, with beef having the largest environmental impact among meat types. Beef provides high

578 levels of important nutrients that cannot easily be achieved by other products. It is therefore not

579 possible to compose a nutritionally equivalent product to beef without the use of fortifications. For

580 future research, more integrated and comprehensive analyses of the role of replacers within the diet

581 and the supply systems of ingredients are required. In this context, more standardized data and better

582 knowledge with regards to the environmental impact of different products and geographical regions

583 are needed. 


\section{Acknowledgements}

585 This research was conducted as part of the project Greendish (ALWGroen.2014.017), funded by The

586 Netherlands Organisation for Scientific Research (NWO). We gratefully acknowledge Roline

587 Broekema of Blonk Consultants and Bertran Averink of Vivera for the provision of data and

588 information during this research. 


\section{References}

590 Aiking, H. (2011). Future protein supply. Trends in Food Science \& Technology, 22(2), 112-120.

Arima, E. Y., Richards, P., Walker, R., \& Caldas, M. M. (2011). Statistical confirmation of indirect land use change in the Brazilian Amazon. Environmental Research Letters, 6(2), 024010.

Asgar, M. A., Fazilah, A., Huda, N., Bhat, R., \& Karim, A. A. (2010). Nonmeat Protein Alternatives as Meat Extenders and Meat Analogs. Comprehensive Reviews in Food Science and Food Safety, 9(5), 513-529. doi: 10.1111/j.1541-4337.2010.00124.x

Aubé, F. (2001). Guide for computing CO2 emissions associated with energy use: CANMET Energy Diversification Research Laboratory

Avadí, A., Fréon, P., \& Quispe, I. (2014). Environmental assessment of Peruvian anchoveta food products: is less refined better? The International Journal of Life Cycle Assessment, 19(6), 1276-1293. doi: 10.1007/s11367-014-0737-y

Averink, B. (2015). [Vivera product information (Personal communication)].

Barona, E., Ramankutty, N., Hyman, G., \& Coomes, O. T. (2010). The role of pasture and soybean in deforestation of the Brazilian Amazon. Environmental Research Letters, 5(2), 024002.

Baroni, L., Cenci, L., Tettamanti, M., \& Berati, M. (2006). Evaluating the environmental impact of various dietary patterns combined with different food production systems. 61(2), 279-286.

Bender, A. (1992). Meat and health. In FAO (Ed.), Meat and meat products in human nutrition in developing countries. Rome.

Berners-Lee, M., Hoolohan, C., Cammack, H., \& Hewitt, C. N. (2012). The relative greenhouse gas impacts of realistic dietary choices. Energy Policy, 43, 184-190.

Billen, G., Lassaletta, L., \& Garnier, J. (2014). A biogeochemical view of the global agro-food system: Nitrogen flows associated with protein production, consumption and trade. Global Food Security, 3(3), 209-219.

Blonk Agri Footprint BV. (2015). Agri-footprint 2.0 - Part 1: Methodology and basic principles. Gouda.

Blonk, H., Alvarado, C., \& De Schryver, A. (2007). Milieuanalyse vleesproducten: PRé Consultants B.V. \& Blonk Milieu Advies.

Blonk, H., Kool, A., \& Luske, B. (2008). Milieueffecten van Nederlandse consumptie van eiwitrijke producten.

Broekema, R., \& Blonk, H. (2009). Milieukundige vergelijking van vleesvervangers: Blonk Milieu Advies BV.

Broekema, R., \& Smale, E. (2011). Nulmeting Peulvruchten, Inzicht in milieueffecten en nutritionele aspecten van peulvruchten: Blonk Milieu Advies BV.

Bukkens, S. G. F. (1997). The nutritional value of edible insects. Ecology of Food and Nutrition, 36(24), 287-319. doi: 10.1080/03670244.1997.9991521

Castanheira, É. G., \& Freire, F. (2013). Greenhouse gas assessment of soybean production: implications of land use change and different cultivation systems. Journal of Cleaner Production, 54, 49-60.

Castellini, C., Boggia, A., Paolotti, L., Thoma, G. J., \& Kim, D. (2012). Environmental Impacts and Life Cycle Analysis of Organic Meat Production and Processing Organic Meat Production and Processing (pp. 113-136): Wiley-Blackwell.

Cerutti, A. K., Bruun, S., Beccaro, G. L., \& Bounous, G. (2011). A review of studies applying environmental impact assessment methods on fruit production systems. Journal of Environmental Management, 92(10), 2277-2286.

Coe, M. T., Marthews, T. R., Costa, M. H., Galbraith, D. R., Greenglass, N. L., Imbuzeiro, H. M., ... \& Powell, T. L. (2013). Deforestation and climate feedbacks threaten the ecological integrity of south-southeastern Amazonia. Phil. Trans. R. Soc. B, 368(1619), 20120155.

Costa, M. H., Yanagi, S. N., Souza, P. J., Ribeiro, A., \& Rocha, E. J. (2007). Climate change in Amazonia caused by soybean cropland expansion, as compared to caused by pastureland expansion. Geophysical Research Letters, 34(7).

Davis, A., Nguyen, H., Gargia-bravo, R., Fiorotto, M., Jacksonz, E., \& Reeds, P. (1994). Amino acid composition of the milk of some mammalian species changes with stage of lactation. British Journul of Nutrition, 72, 845-853. 
Davis, J., Sonesson, U., Baumgartner, D. U., \& Nemecek, T. (2010). Environmental impact of four meals with different protein sources: Case studies in Spain and Sweden. Food Research International, 43(7), 1874-1884. doi: http://dx.doi.org/10.1016/j.foodres.2009.08.017

Day, L. (2013). Proteins from land plants-potential resources for human nutrition and food security. Trends in Food Science \& Technology, 32(1), 25-42.

de Vries, M., \& de Boer, I. J. M. (2010). Comparing environmental impacts for livestock products: A review of life cycle assessments. Livestock Science, 128(1-3), 1-11.

FAO. (2004). Protein sources for the animal feed industry. FAO.

FAO. (2009). Global agriculture towards 2050, Rome: FAO high-level expert forum

FAO/INFOODS. (2013). FAO/INFOODS Food Composition Database for Biodiversity Version 2.1 BioFoodComp2.1 from FAO

FAO/WHO. (2002). Human Vitamin and Mineral Requirements Bangkok, Thailand: World Health Organisation

FAO/WHO/UNU. (2002). Protein and amino acid requirements in human nutrition WHO technical report series (Vol. 935). Geneva, Switzerland: WHO.

Fearnside, P. M. (2016). Brazil's Amazonian forest carbon: the key to Southern Amazonia's significance for global climate. Regional Environmental Change, 1-15.

Fiala, N. (2008). Meeting the demand: An estimation of potential future greenhouse gas emissions from meat production. Ecological Economics, 67(3), 412-419. doi: http://dx.doi.org/10.1016/j.ecolecon.2007.12.021

Finnveden, G., Hauschild, M. Z., Ekvall, T., Guinée, J., Heijungs, R., Hellweg, S., . . Suh, S. (2009). Recent developments in Life Cycle Assessment. Journal of Environmental Management, 91(1), 1-21.

Flindall. Vitaminen van Flinndal Retrieved 06/04/2016, from https://www.flinndal.nl/

Foster, C., Guében, C., Holmes, M., Wiltshire, J., \& Wynn, S. (2014). The environmental effects of seasonal food purchase: a raspberry case study. Journal of Cleaner Production, 73, 269-274.

Friedman, M. (1996). Nutritional Value of Proteins from Different Food Sources. A Review. Journal of Agricultural and Food Chemistry, 44(1), 6-29.

Garnett, T. (2009). Livestock-related greenhouse gas emissions: impacts and options for policy makers. Environmental Science \& Policy, 12(4), 491-503.

Garnett, T. (2013). Food sustainability: problems, perspectives and solutions. Proceedings of the Nutrition Society, 72(1), 29-39. doi: 10.1017/s0029665112002947

Gasparri, N. I., Grau, H. R., \& Angonese, J. G. (2013). Linkages between soybean and neotropical deforestation: coupling and transient decoupling dynamics in a multi-decadal analysis. Global Environmental Change, 23(6), 1605-1614.

Goedkoop, M., Heijungs, R., Huijbregts, M., De Schryver, A., Struijs, J., \& van Zelm, R. (2013). ReCiPe 2008: A life cycle impact assessment method which comprises harmonised category indicators at the midpoint and the endpoint level.

Hallström, E., Carlsson-Kanyama, A., \& Börjesson, P. (2015). Environmental impact of dietary change: a systematic review. Journal of Cleaner Production, 91, 1-11. doi: http://dx.doi.org/10.1016/j.jclepro.2014.12.008

Hauschild, M., Goedkoop, M., Guinée, J., Heijungs, R., Huijbregts, M., Jolliet, O., . . Pant, R. (2013). Identifying best existing practice for characterization modeling in life cycle impact assessment. The International Journal of Life Cycle Assessment, 18(3), 683-697. doi: 10.1007/s11367-012-0489-5

Health Council of the Netherlands. (2011). Guidelines for a healthy diet: the ecological perspective. The Hague.

Hendriks, T. H. B. (2013). Duality and sensitivity analysis In G. D. H. Claassen, T. H. B. Hendriks \& E. M. T. Hendrix (Eds.), Decision science. Wageningen Wageningen Academic Publishers

Ingwersen, W. W. (2012). Life cycle assessment of fresh pineapple from Costa Rica. Journal of Cleaner Production, 35, 152-163.

Lima, M., Skutsch, M., \& de Medeiros Costa, G. (2011). Deforestation and the social impacts of soy for biodiesel: perspectives of farmers in the South Brazilian Amazon. Ecology and Society, 16(4). 
Macdiarmid, J. I., Kyle, J., Horgan, G. W., Loe, J., Fyfe, C., Johnstone, A., \& McNeill, G. (2012). Sustainable diets for the future: can we contribute to reducing greenhouse gas emissions by eating a healthy diet?. The American journal of clinical nutrition, 96(3), 632-639.

Macedo, M. N., DeFries, R. S., Morton, D. C., Stickler, C. M., Galford, G. L., \& Shimabukuro, Y. E. (2012). Decoupling of deforestation and soy production in the southern Amazon during the late 2000s. Proceedings of the National Academy of Sciences, 109(4), 1341-1346.

Margni, M., \& Curran, M. A. (2012). Life Cycle Impact Assessment Life Cycle Assessment Handbook (pp. 67-103): John Wiley \& Sons, Inc.

Meier, M. S., Stoessel, F., Jungbluth, N., Juraske, R., Schader, C., \& Stolze, M. (2015). Environmental impacts of organic and conventional agricultural products - Are the differences captured by life cycle assessment? Journal of Environmental Management, 149, 193-208.

Meier, T., \& Christen, O. (2012). Environmental impacts of dietary recommendations and dietary styles: Germany as an example. Environmental science \& technology, 47(2), 877-888.

Mekonnen, M. M., \& Hoekstra, A. Y. (2011). The green, blue and grey water footprint of crops and derived crop products. Hydrology and Earth System Sciences, 15(5), 1577-1600.

Mekonnen, M. M., \& Hoekstra, A. Y. (2013). A global assessment of the water footprint of farm animal products. Ecosystems, 15(3), 401-415.

Mishra, N., El-Aal Bakr, A. A., Niranjan, K., \& Tucker, G. (2011). Environmental Aspects of Food Processing Food Processing Handbook (pp. 571-591): Wiley-VCH Verlag GmbH \& Co. KGaA.

Mogensen, L., Hermansen, J. E., Halberg, N., Dalgaard, R., Vis, J. C., \& Smith, B. G. (2009). Life Cycle Assessment Across the Food Supply Chain Sustainability in the Food Industry (pp. 115144): A John Wiley \& Sons, Ltd.

Mollenhorst, H., Berentsen, P. B. M., \& De Boer, I. J. M. (2006). On-farm quantification of sustainability indicators: an application to egg production systems. British Poultry Science, 47(4), 405-417. doi: 10.1080/00071660600829282

Monsen, E., Hallberg, L., Layrisse, M., Hegsted, D., Cook, J., Mertz, W., \& Finch, C. (1978). Estimation of available dietary iron. American Journal of Clinical Nutrition, 31(1), 134-141.

Nijdam, D., Rood, T., \& Westhoek, H. (2012). The price of protein: Review of land use and carbon footprints from life cycle assessments of animal food products and their substitutes. Food Policy, 37(6), 760-770.

Notarnicola, B., Tassielli, G., Renzulli, P. A., Castellani, V., \& Sala, S. (2017). Environmental impacts of food consumption in Europe. Journal of Cleaner Production, 140, Part 2, 753-765. doi: http://dx.doi.org/10.1016/j.jclepro.2016.06.080

Oonincx, D., \& de Boer, I. (2012). Environmental Impact of the Production of Mealworms as a Protein Source for Humans - A Life Cycle Assessment. PLoS ONE, 7(12).

Pardo, G., \& Zufía, J. (2012). Life cycle assessment of food-preservation technologies. Journal of Cleaner Production, 28, 198-207.

Persson, U. M., Henders, S., \& Cederberg, C. (2014). A method for calculating a land-use change carbon footprint (LUC-CFP) for agricultural commodities-applications to Brazilian beef and soy, Indonesian palm oil. Global change biology, 20(11), 3482-3491.

RIVM. (2013). Nederlands Voedingsstoffenbestand (online database).

Romero, C. (2001). Extended lexicographic goal programming: a unifying approach. Omega, 29(1), 63-71. doi: http://dx.doi.org/10.1016/S0305-0483(00)00026-8

Romero, C., \& Rehman, T. (2003). Chapter five Compromise programming Developments in Agricultural Economics (Vol. 11, pp. 63-78): Elsevier.

Sabaté, J., \& Soret, S. (2014). Sustainability of plant-based diets: back to the future. The American journal of clinical nutrition, 100(Supplement 1), 476S-482S.

Sampaio, G., Nobre, C., Costa, M. H., Satyamurty, P., Soares-Filho, B. S., \& Cardoso, M. (2007). Regional climate change over eastern Amazonia caused by pasture and soybean cropland expansion. Geophysical Research Letters, 34(17).

Sasu-Boakye, Y., Cederberg, C., \& Wirsenius, S. (2014). Localising livestock protein feed production and the impact on land use and greenhouse gas emissions. animal, 8(08), 1339-1348.

Sauer, B. (2012). Life Cycle Inventory Modeling in Practice Life Cycle Assessment Handbook (pp. 4366): John Wiley \& Sons, Inc. 
Schlemmer, U., Frølich, W., Prieto, R. M., \& Grases, F. (2009). Phytate in foods and significance for humans: Food sources, intake, processing, bioavailability, protective role and analysis. Molecular Nutrition \& Food Research, 53, S330 -S375.

Schösler, H., De Boer, J., \& Boersema, J. J. (2012). Can we cut out the meat of the dish? Constructing consumer-oriented pathways towards meat substitution. Appetite, 58(1), 39-47.

da Silva, V. P., van der Werf, H. M., Spies, A., \& Soares, S. R. (2010). Variability in environmental impacts of Brazilian soybean according to crop production and transport scenarios. Journal of environmental management, 91(9), 1831-1839.

Sim, S., Barry, M., Clift, R., \& Cowell, S. (2007). The relative importance of transport in determining an appropriate sustainability strategy for food sourcing. The International Journal of Life Cycle Assessment, 12(6), 422-431. doi: 10.1065/lca2006.07.259

Smetana, S., Mathys, A., Knoch, A., \& Heinz, V. (2015). Meat alternatives: life cycle assessment of most known meat substitutes. The International Journal of Life Cycle Assessment, 20(9), 1254-1267. doi: 10.1007/s11367-015-0931-6

Sonesson, U., Davis, J., Flysjö, A., Gustavsson, J., \& Witthöft, C. (2017). Protein quality as functional unit-A methodological framework for inclusion in life cycle assessment of food. Journal of Cleaner Production, 140, 470-478.

Sonesson, U., Mattsson, B., Nybrant, T., \& Ohlsson, T. (2005). Industrial Processing versus Home Cooking: An Environmental Comparison between Three Ways to Prepare a Meal. Ambio, 34.

Steinfeld, H., Gerber, P., Wassenaar, T., Castel, V., Rosales, M., \& de Haan, C. (2006). Livestock's Long Shadow: Environmental Issues and Options.

Temme, E. H. M., van der Voet, H., Thissen, J. T. N. M., Verkaik-Kloosterman, J., van Donkersgoed, G., \& Nonhebel, S. (2013). Replacement of meat and dairy by plant-derived foods: estimated effects on land use, iron and SFA intakes in young Dutch adult females. Public Health Nutrition, 16(10), 1900-1907. doi: 10.1017/s1368980013000232

Tyszler, M., Kramer, G., \& Blonk, H. (2014). Comparing apples with oranges: on the functional equivalence of food products for comparative LCAs. The International Journal of Life Cycle Assessment, 19(8), 1482-1487.

Tyszler, M., Kramer, G., \& Blonk, H. (2016). Just eating healthier is not enough: studying the environmental impact of different diet scenarios for Dutch women (31-50 years old) by linear programming. The International Journal of Life Cycle Assessment, 21(5), 701-709.

Tukker, A., \& Jansen, B. (2006). Environmental Impacts of Products: A Detailed Review of Studies. Journal of Industrial Ecology, 10(3), 159-182. doi: 10.1162/jiec.2006.10.3.159

USDA. (2016). National Nutrient Database for Standard Reference Release 28 Retrieved 10/03/2016, from United States Department of Agriculture https://ndb.nal.usda.gov/ndb/foods

van Dooren, C., Marinussen, M., Blonk, H., Aiking, H., \& Vellinga, P. (2014). Exploring dietary guidelines based on ecological and nutritional values: A comparison of six dietary patterns. Food Policy, 44, 36-46.

Van Kernebeek, H. R. J., Oosting, S. J., Feskens, E. J. M., Gerber, P. J., \& De Boer, I. J. M. (2014). The effect of nutritional quality on comparing environmental impacts of human diets. Journal of Cleaner Production, 73, 88-99.

Van Kernebeek, H. R., Oosting, S. J., Van Ittersum, M. K., Bikker, P., \& De Boer, I. J. (2016). Saving land to feed a growing population: consequences for consumption of crop and livestock products. The International Journal of Life Cycle Assessment, 21(5), 677-687.

Vermeulen, S. J., Campbell, B. M., \& Ingram, J. S. I. (2012). Climate Change and Food Systems. Annual Review of Environment and Resources, 37(1), 195-222. doi: doi:10.1146/annurevenviron-020411-130608

Viglizzo, E. F., Frank, F. C., Carreno, L. V., Jobbagy, E. G., Pereyra, H., Clatt, J., ... \& RICARD, M. F. (2011). Ecological and environmental footprint of 50 years of agricultural expansion in Argentina. Global Change Biology, 17(2), 959-973.

Vivera. (2016). The Vivera product range Retrieved 10/03/2016, from http://www.vivera.com/en/home

Voedingscentrum. (2016). Gezonde voeding en voedinsstoffen, 2016, from http://www.voedingscentrum.nl/nl.aspx 
Weidema, B. P., Bauer, C., Hischier, R., Mutel, C., Nemecek, T., Reinhard, J., . . Wernet, G. (2013). Overview and methodology. Data quality guideline for the ecoinvent database version 3. Ecoinvent Report 1 (v3). St. Gallen: The ecoinvent Centre.

Weidema, B. P., \& Eder, P. (2008). Environmental improvement potentials of meat and dairy products Joint Research Centre Institute for Prospective Technological Studies.

Wernet, G., Bauer, C., Steubing, B., Reinhard, J., Moreno-Ruiz, E., \& Weidema, B. (2016). The ecoinvent database version 3 (part I): overview and methodology. The International Journal of Life Cycle Assessment, 21(9), 1218-1230.

Wilson, N., Nghiem, N., Ni Mhurchu, C., Eyles, H., Baker, M. G., \& Blakely, T. (2013). Foods and Dietary Patterns That Are Healthy, Low-Cost, and Environmentally Sustainable: A Case Study of Optimization Modeling for New Zealand. PLoS ONE, 8(3), e59648. doi: 10.1371/journal.pone.0059648

Wu, G., Fanzo, J., Miller, D. D., Pingali, P., Post, M., Steiner, J. L., \& Thalacker-Mercer, A. E. (2014). Production and supply of high-quality food protein for human consumption: sustainability, challenges, and innovations. Annals of the New York Academy of Sciences, 1321(1), 1-19.

Zhu, X., \& van Ierland, E. C. (2004). Protein Chains and Environmental Pressures: A Comparison of Pork and Novel Protein Foods. Environmental Sciences, 1(3), 254-276. doi: $10.1080 / 15693430412331291652$ 


\section{A. Required contents of nutrients}

827 The required nutrient contents for the meat replacers are based on the nutritional value of the references chicken $(k=1)$ and beef $(k=2)$. The references' contents of protein, iron, vitamin B12 and zinc are used as lower bounds $\left(r n_{j, k}\right)$ for the meat replacer.

The required contents of essential amino acids are based on the human requirements for these amino acids. They are calculated by multiplying the human requirement of the amino acid (mg/g protein) with the protein content of the references chicken and beef.

Iron can be found in two forms: heme iron and non-heme iron, of which the latter is less absorbable by

834 the human body (Bender, 1992). Meat contains both forms, but in non-meat products only non-heme

835 iron is present (Monsen et al., 1978). The required amount of iron ( $\left.r c_{i r o n, k}\right)$ is expressed in terms of

836 non-heme iron. It is calculated by summing the amount of non-heme iron with the amount of heme

837 iron in the reference $k$, multiplied with a conversion factor to take the difference in absorbability into

838 account:

$839 r c_{\text {iron }, k}=$ non-heme-iron $_{k}+\left(\right.$ heme iron $_{k} \cdot$ conversion factor $)$

840 The conversion factor is calculated by dividing the absorbability of heme iron (23\% (Monsen et al.,

841 1978)) with the absorbability of non-heme iron (8\% (Monsen et al., 1978)).

842 Table A-1 shows the considered nutrients, their corresponding index $j$ and their required amount in the

843 meat replacers, both when chicken and beef are used as reference.

844 Table A-1. Considered nutrients ( $j)$, their units and their required content in the meat replacer, both when chicken and beef 845 are used as references.

\begin{tabular}{rlrcc}
\hline & & & Reference $=$ chicken & Reference $=$ beef \\
\hline $\boldsymbol{j}$ & Name & Unit & $\left(\boldsymbol{r n}_{\boldsymbol{j}, \boldsymbol{l}}\right)$ & $\left(\boldsymbol{r n}_{\boldsymbol{j}, 2}\right)$ \\
\hline 1 & Energy & $\mathrm{kJ} / 100 \mathrm{~g}$ & 667 & 679 \\
2 & Protein & $\mathrm{g} / 100 \mathrm{~g}$ & 30.9 & 29.7 \\
3 & Isoleucine & $\mathrm{g} / 100 \mathrm{~g}$ & 0.93 & 0.89 \\
4 & Leucine & $\mathrm{g} / 100 \mathrm{~g}$ & 1.82 & 1.75 \\
5 & Lysine & $\mathrm{g} / 100 \mathrm{~g}$ & 1.39 & 1.34 \\
6 & Methionine + cysteine & $\mathrm{g} / 100 \mathrm{~g}$ & 0.68 & 0.65 \\
7 & Phenylalanine + tyrosine & $\mathrm{g} / 100 \mathrm{~g}$ & 1.17 & 1.13 \\
8 & Threonine & $\mathrm{g} / 100 \mathrm{~g}$ & 0.71 & 0.68 \\
9 & Tryptophan & $\mathrm{g} / 100 \mathrm{~g}$ & 0.19 & 0.18 \\
10 & Valine & $\mathrm{g} / 100 \mathrm{~g}$ & 1.21 & 1.16 \\
11 & Iron (non-heme) & $\mathrm{mg} / 100 \mathrm{~g}$ & 2.03 & 6.46 \\
12 & Vitamin B12 & $\mu \mathrm{g} / 100 \mathrm{~g}$ & 0.29 & 2.11 \\
13 & Zinc & $\mathrm{mg} / 100 \mathrm{~g}$ & 0.74 & 6.45 \\
\hline
\end{tabular}


847 Life Cycle Assessment (LCA) is a method to determine the environmental impact of a product's entire

848 life cycle, from agricultural production ('cradle') to the consumption and the recycling of the product

849 ('grave'). An LCA consists of four steps: goal \& scope definition, inventory analysis, impact

850 assessment and interpretation (Mogensen et al., 2009). The goal and scope definition aims to define

851 the studied supply chain, the functional unit, the system boundaries, the impact indicators and applied

852 methods (Sauer, 2012). The life cycle inventory contains all the data related to the used resources and

853 emissions to the environment that occur during the life cycle of a product. The data are quantified in

854 relation to the defined functional unit (Finnveden et al., 2009), for example one kilogram of end

855 product (Sauer, 2012). The impact assessment aims to evaluate the environmental impact of the

856 resources and emissions that are reported in the inventory analysis (Margni \& Curran, 2012). The

857 environmental impact is expressed in terms of environmental impact indicators, for which values are

858 quantified. In the interpretation step of the LCA, the results of the inventory analysis and the impact

859 assessment are evaluated to take decisions related to the goal of the LCA (Margni \& Curran, 2012).

860 LCA studies of food products often deviate in terms of selected impact indicators, functional unit,

861 system boundaries and applied methods. This can cause different results among LCA studies that

862 investigate the same product or process (Margni \& Curran, 2012). When comparing different LCA

863 studies, it should be made sure that the functional unit, system boundaries and allocation method

864 correspond (de Vries \& de Boer, 2010). For example, when the system boundary of one study includes

865 all the life cycle stages from agricultural production to consumption (from cradle to grave) and another

866 study only includes the agricultural phase (from cradle to farm gate), their results cannot be compared.

867 Moreover, there is no standardized method for selecting LCA impact indicators for a certain product

868 (Cerutti et al., 2011). Therefore, we analyzed existing LCA studies of food products and their impact

869 indicators, in which we characterized the quality and applicability of the indicators. Table B-1 shows

870 the analyzed studies, the applied impact indicators and their characteristics. 
Table B-1. Reviewed studies and their applied impact indicators. Sources: (Smetana et al., 2015; Avadi et al., 2014;

878 Frequently applied indicators are useful since their results can be compared with results of previously executed studies. Similarly, they are reproducible for future studies. As can be seen in Table B-1, climate change is used in all the investigated LCA studies. After that, land use, acidification and eutrophication were the most frequently used indicators. Ozone layer depletion, photochemical ozone formation, eco toxicity, water use and energy use where less frequently used, but also appear in a considerable number of studies. Each impact indicator affects one or more Areas of Protection (AoPs), namely natural resources, natural environment and human health (Margni \& Curran, 2012). Table B-1 indicates for each impact indicator which AoP(s) they affect. Multiple impact assessment methods exist and they often deviate from each other. Hauschild et al (2013) investigate for a number of impact indicators which assessment method is most suitable and if the quality of this method is sufficient to be recommended. If the methods are recommended, they are classified in three categories, based on their quality: (1) recommended and satisfactory, (2) recommended but in need of some improvements and (3) recommended but to be applied with caution. Impact indicators for which a model of category

8911 exists are climate change and ozone layer depletion. Impact indicators for which only models of category 2 exist are photochemical ozone formation, acidification, eutrophication and resource 
depletion (water and mineral resources) (Hauschild et al., 2013). The most frequently used impact

894 indicators correspond with the ones that can be assessed with a method of category 1 or 2 , except for

895 land use. Land use is classified in the third category, so the existing method should be applied with

896 caution. Some impact indicators influence the global environment and some indicators influence only

897 the local environment, which makes their impact highly dependent on local conditions. Impact

898 indicators that influence the global environment are climate change and ozone layer depletion

899 (Finnveden et al., 2009). The fact that they influence the global environment, means that they can be

900 easily compared and applied to other products and other countries. According to Davis et al (2010),

901 some impact indicators are particularly related to food production, including climate change,

902 photochemical ozone formation, acidification, eutrophication, energy use and fossil fuel depletion

903 (Davis et al., 2010). Water use is also related to food since agriculture alone already contributes for

$90470-85 \%$ to the global water footprint (Smetana et al., 2015). Additionally, food processing operations

905 require a lot of energy and water (Mishra et al., 2011). Land use is an important impact category when

906 it comes to feed and food (Smetana et al., 2015) and as can be seen from Table B-1, it is used in a

907 large number of LCA studies of food products.

908 
911 Table $\mathrm{C}-1$ provides the nutritional data of the model ingredients. Table $\mathrm{C}-2$ provides the

912 environmental data of the ingredients and Table $\mathrm{C}-3$ provide the environmental data of the references.

913 Table C-1. Nutritional value of the model ingredients. Source: (RIVM, 2013), except when indicated with a letter. a:(USDA,

914 2016), b: (Broekema \& Smale, 2011), c:(Friedman, 1996), d: (Davis et al., 1994), e:(FAO/INFOODS, 2013), f:(Flindall).

915 The nutritional values of the protein concentrates and isolates of the legumes are calculated from the nutritional value of the

916 corresponding flours, except for soy.

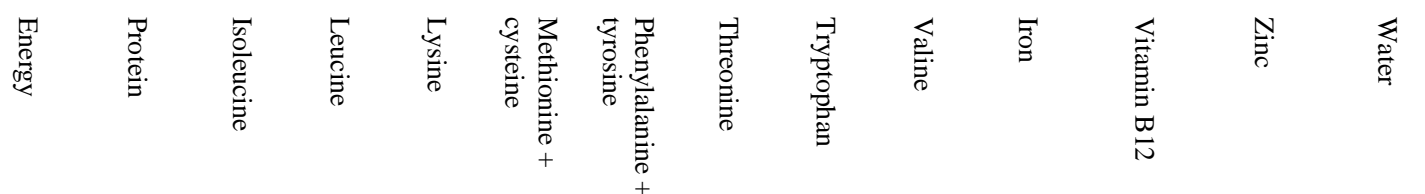

Nutritional value (per 100g)

\begin{tabular}{|c|c|c|c|c|c|c|c|c|c|c|c|c|c|c|c|}
\hline & Unit & $\mathrm{kJ}$ & $\mathrm{g}$ & $\mathrm{g}$ & g & g & g & g & g & $\mathrm{g}$ & $\mathrm{g}$ & $\mathrm{mg}$ & $\mu \mathrm{g}$ & $\mathrm{mg}$ & $\mathrm{g}$ \\
\hline $\mathbf{X} 1$ & Chickpea Flour & $1619^{\mathrm{a}}$ & $22.40^{\mathrm{a}}$ & $0.96^{\mathrm{b}}$ & $1.59^{\mathrm{b}}$ & $1.50^{\mathrm{b}}$ & $0.59^{\mathrm{b}}$ & $1.76^{\mathrm{b}}$ & $0.83^{\mathrm{b}}$ & $0.22^{\mathrm{b}}$ & $0.94^{b}$ & $4.86^{\mathrm{a}}$ & $0.00^{\mathrm{a}}$ & $2.81^{\mathrm{a}}$ & 10.30 \\
\hline $\mathbf{X} 2$ & Chickpea protein concentrate & 1245 & 36.00 & 1.56 & 2.58 & 2.43 & 0.96 & 2.84 & 1.35 & 0.35 & 1.52 & 5.53 & 0.00 & 4.05 & 5.24 \\
\hline $\mathbf{X 3}$ & Chickpea protein isolate & 1272 & 50.36 & 2.16 & 3.59 & 3.37 & 1.33 & 3.95 & 1.87 & 0.48 & 2.12 & 7.44 & 0.00 & 3.71 & 4.50 \\
\hline $\mathbf{X} 4$ & Kidney bean flour & 1324 & 20.10 & $0.89^{\mathrm{b}}$ & $1.60^{\mathrm{b}}$ & $1.38^{\mathrm{b}}$ & $0.52^{\mathrm{b}}$ & $1.65^{\mathrm{b}}$ & $0.84^{\mathrm{b}}$ & $0.24^{\mathrm{b}}$ & $1.05^{\mathrm{b}}$ & 5.00 & 0.00 & 2.00 & 11.40 \\
\hline X5 & Kidney bean protein concentrate & 1042 & 35.63 & 1.57 & 2.84 & 2.45 & 0.92 & 2.93 & 1.50 & 0.42 & 1.86 & 6.42 & 0.00 & 2.93 & 7.78 \\
\hline X6 & Kidney bean protein isolate & 1065 & 49.45 & 2.18 & 3.95 & 3.40 & 1.28 & 4.06 & 2.08 & 0.58 & 2.59 & 8.63 & 0.00 & 2.69 & 6.68 \\
\hline $\mathbf{X 7}$ & Lentil flour & 1289 & 21.00 & $0.91^{b}$ & $1.52^{\mathrm{b}}$ & $1.47^{\mathrm{b}}$ & $0.45^{\mathrm{b}}$ & $1.60^{\mathrm{b}}$ & $0.75^{b}$ & $0.19^{\mathrm{b}}$ & $1.04^{\mathrm{b}}$ & 5.00 & 0.00 & 3.50 & 12.00 \\
\hline X8 & Lentil protein concentrate & 1014 & 37.22 & 1.61 & 2.70 & 2.60 & 0.80 & 2.83 & 1.33 & 0.33 & 1.85 & 6.42 & 0.00 & 5.13 & 8.19 \\
\hline X9 & Lentil protein isolate & 1036 & 51.66 & 2.23 & 3.75 & 3.61 & 1.12 & 3.93 & 1.85 & 0.46 & 2.57 & 8.63 & 0.00 & 4.70 & 7.03 \\
\hline $\mathrm{X} 10$ & Lupine flour & $1552^{\mathrm{a}}$ & $36.17^{\mathrm{a}}$ & $1.61^{\mathrm{b}}$ & $2.75^{b}$ & $1.93^{\mathrm{b}}$ & $0.70^{\mathrm{b}}$ & $2.80^{\mathrm{b}}$ & $1.33^{\mathrm{b}}$ & $0.29^{\mathrm{b}}$ & $1.51^{\mathrm{b}}$ & $4.36^{\mathrm{a}}$ & $0.00^{\mathrm{a}}$ & $4.75^{\mathrm{a}}$ & 10.44 \\
\hline $\mathbf{X 1 1}$ & Lupine protein concentrate & 1222 & 64.41 & 2.86 & 4.87 & 3.42 & 1.24 & 4.96 & 2.36 & 0.51 & 2.67 & 5.60 & 0.00 & 6.97 & 7.12 \\
\hline $\mathrm{X} 12$ & Lupine protein isolate & 1248 & 88.98 & 3.97 & 6.75 & 4.75 & 1.73 & 6.88 & 3.27 & 0.71 & 3.71 & 7.53 & 0.00 & 6.38 & 6.12 \\
\hline $\mathbf{X 1 3}$ & Pea flour & 1527 & 23.40 & $0.82^{b}$ & $1.91^{b}$ & $1.68^{\mathrm{b}}$ & $0.36^{\mathrm{b}}$ & $1.57^{\mathrm{b}}$ & $0.82^{\mathrm{b}}$ & $0.23^{\mathrm{b}}$ & $2.28^{b}$ & 4.40 & 0.00 & 3.00 & 12.00 \\
\hline X14 & Pea protein concentrate & 1043 & 37.22 & 1.31 & 3.04 & 2.68 & 0.57 & 2.50 & 1.31 & 0.36 & 3.63 & 6.42 & 0.00 & 5.13 & 8.19 \\
\hline X15 & Pea protein isolate & 1066 & 51.66 & 1.82 & 4.22 & 3.71 & 0.79 & 3.48 & 1.82 & 0.51 & 5.04 & 8.63 & 0.00 & 4.70 & 7.03 \\
\hline X16 & Soy flour & 1997 & 38.00 & $1.79^{c}$ & $3.23^{\mathrm{c}}$ & $2.41^{\mathrm{c}}$ & $2.59^{\mathrm{c}}$ & $3.67^{\mathrm{c}}$ & $1.46^{\mathrm{c}}$ & $0.43^{\mathrm{c}}$ & $1.87^{\mathrm{c}}$ & 6.90 & 0.00 & 5.00 & 7.00 \\
\hline $\mathbf{X 1 7}$ & Soy protein concentrate & $1372^{\mathrm{a}}$ & $63.63^{\mathrm{a}}$ & 3.00 & 5.41 & 4.03 & 4.33 & 6.15 & 2.44 & 0.73 & 3.12 & $10.78^{\mathrm{a}}$ & $0.00^{\mathrm{a}}$ & $4.40^{\mathrm{a}}$ & 5.80 \\
\hline X18 & Soy protein isolate & $1402^{\mathrm{a}}$ & $88.32^{\mathrm{a}}$ & 4.16 & 7.52 & 5.60 & 6.01 & 8.53 & 3.39 & 1.01 & 4.34 & $14.50^{\mathrm{a}}$ & $0.00^{\mathrm{a}}$ & $4.03^{\mathrm{a}}$ & 4.98 \\
\hline X19 & Wheat flour & 1386 & 10.00 & $0.33^{c}$ & $0.69^{\mathrm{c}}$ & $0.27^{\mathrm{c}}$ & $0.39^{\mathrm{c}}$ & $0.78^{\mathrm{c}}$ & $0.29^{c}$ & $0.11^{\mathrm{c}}$ & $0.43^{\mathrm{c}}$ & 4.00 & 0.00 & 2.90 & 15.00 \\
\hline $\mathbf{X} 20$ & Wheat protein concentrate & 1091 & 17.72 & 0.59 & 1.21 & 0.47 & 0.69 & 1.38 & 0.52 & 0.20 & 0.76 & 5.13 & 0.00 & 4.25 & 10.24 \\
\hline $\mathbf{X} 21$ & Wheat protein isolate (gluten) & 1115 & 24.60 & 0.82 & 1.69 & 0.65 & 0.95 & 1.91 & 0.72 & 0.28 & 1.05 & 6.90 & 0.00 & 3.90 & 8.79 \\
\hline $\mathbf{X} 22$ & Eggs & 549 & 12.30 & $0.65^{\mathrm{c}}$ & $1.08^{\mathrm{c}}$ & $0.86^{\mathrm{c}}$ & $0.82^{\mathrm{c}}$ & $1.12^{\mathrm{c}}$ & $0.58^{\mathrm{c}}$ & $0.18^{\mathrm{c}}$ & $0.83^{\mathrm{c}}$ & 2.20 & 1.49 & 1.56 & 76.2 \\
\hline $\mathrm{X} 23$ & Cheese & 1526 & 22.80 & $1.07^{\mathrm{d}}$ & $2.26^{\mathrm{d}}$ & $1.96^{\mathrm{d}}$ & $0.78^{d}$ & $2.21^{\mathrm{d}}$ & $0.96^{\mathrm{d}}$ & $0.00^{\mathrm{d}}$ & $1.19^{\mathrm{d}}$ & 0.20 & 1.97 & 3.47 & 39.3 \\
\hline $\mathbf{X} 24$ & Meal worms & $577^{\mathrm{e}}$ & $23.70^{\mathrm{e}}$ & $1.03^{\mathrm{e}}$ & $1.96^{\mathrm{e}}$ & $1.05^{\mathrm{e}}$ & $0.46^{\mathrm{e}}$ & $1.41^{\mathrm{e}}$ & $0.81^{\mathrm{e}}$ & $0.26^{\mathrm{e}}$ & $1.50^{\mathrm{e}}$ & $2.18^{\mathrm{e}}$ & $0.56^{\mathrm{e}}$ & $4.62^{\mathrm{e}}$ & 63.70 \\
\hline $\mathrm{X} 25$ & Super worms & $1014^{\mathrm{e}}$ & $19.70^{\mathrm{e}}$ & $0.93^{\mathrm{e}}$ & $1.91^{\mathrm{e}}$ & $1.03^{\mathrm{e}}$ & $0.36^{\mathrm{e}}$ & $2.05^{\mathrm{e}}$ & $0.78^{\mathrm{e}}$ & $0.18^{\mathrm{e}}$ & $1.03^{\mathrm{e}}$ & $1.65^{\mathrm{e}}$ & $0.42^{\mathrm{e}}$ & $3.07^{\mathrm{e}}$ & 57.9 \\
\hline $\mathrm{X} 26$ & Water & 0 & 0.00 & 0.00 & 0.00 & 0.00 & 0.00 & 0.00 & 0.00 & 0.00 & 0.00 & $\begin{array}{c}0.00 \\
5.79 \mathrm{E}\end{array}$ & 0.00 & 0.00 & 100.00 \\
\hline $\mathbf{X} 27$ & Iron fortification & 1.50 & 0.00 & 0.00 & 0.00 & 0.00 & 0.00 & 0.00 & 0.00 & 0.00 & 0.00 & $+03^{\mathrm{f}}$ & $\begin{array}{c}0.00 \\
5.38 \mathrm{E}+\end{array}$ & 0.00 & 0.00 \\
\hline $\mathrm{X} 28$ & B12 fortification & 3.11 & 0.00 & 0.00 & 0.00 & 0.00 & 0.00 & 0.00 & 0.00 & 0.00 & 0.00 & 0.00 & $05^{\mathrm{f}}$ & $\begin{array}{c}0.00 \\
5.95 \mathrm{E}+\end{array}$ & 0.00 \\
\hline $\mathbf{X} 29$ & Zinc fortification & 0.36 & 0.00 & 0.00 & 0.00 & 0.00 & 0.00 & 0.00 & 0.00 & 0.00 & 0.00 & 0.00 & 0.00 & $03^{\mathrm{f}}$ & 0.00 \\
\hline
\end{tabular}


Table C-2. Environmental data of model ingredients. Source: (Broekema \& Smale, 2011), except when indicated with a

918 letter. a: (Mekonnen \& Hoekstra, 2011), b: (Mekonnen \& Hoekstra, 2013), c: (de Vries \& de Boer, 2010), d: (van Middelaar

919 et al., 2011), e:(Oonincx \& de Boer, 2012). The environmental values of the protein concentrates and isolates of chickpeas,

920 kidney beans, lentils and wheat are calculated from the values of the corresponding flours. The environmental values of the

921 fortifications and water are based on assumptions.

\begin{tabular}{|c|c|c|c|c|c|}
\hline & $\begin{array}{l}\text { Environmental impact (per kg) } \\
\text { Unit }\end{array}$ & $\begin{array}{c}\text { Climate change } \\
\mathrm{kg} \mathrm{CO}_{2} \mathrm{eq}\end{array}$ & $\begin{array}{l}\text { Land use } \\
\mathrm{m}^{2} / \text { year }\end{array}$ & $\begin{array}{c}\text { Water use } \\
\text { m3 }\end{array}$ & $\begin{array}{c}\text { Fossil fuel depletion } \\
\text { MJ } \\
\end{array}$ \\
\hline $\mathbf{X 1}$ & Chickpea flour & 0.99 & 8.42 & $0.266 \mathrm{a}$ & 13.82 \\
\hline $\mathbf{X} 2$ & Chickpea protein concentrate & 1.45 & 9.64 & 0.266 & 29.89 \\
\hline $\mathbf{X 3}$ & Chickpea protein isolate & 3.13 & 18.42 & 0.266 & 51.16 \\
\hline $\mathbf{X} 4$ & Kidney bean flour & 1.47 & 3.69 & $0.148^{\mathrm{a}}$ & 14.62 \\
\hline X5 & Kidney bean protein concentrate & 2.16 & 4.22 & 0.148 & 31.61 \\
\hline X6 & Kidney bean protein isolate & 4.65 & 8.07 & 0.148 & 54.11 \\
\hline $\mathbf{X 7}$ & Lentil flour & 1.00 & 7.71 & $0.580^{\mathrm{a}}$ & 12.93 \\
\hline $\mathbf{x 8}$ & Lentil protein concentrate & 1.47 & 8.83 & 0.580 & 27.96 \\
\hline X9 & Lentil protein isolate & 3.16 & 16.87 & 0.580 & 47.86 \\
\hline $\mathbf{X 1 0}$ & Lupine flour & 1.06 & 7.77 & $0.173^{\mathrm{a}}$ & 10.48 \\
\hline X11 & Lupine protein concentrate & 1.24 & 9.16 & 0.173 & 12.34 \\
\hline X12 & Lupine protein isolate & 3.28 & 15.66 & 0.025 & 38.47 \\
\hline X13 & Pea flour & 0.62 & 2.79 & $0.173^{\mathrm{a}}$ & 6.24 \\
\hline X14 & Pea protein concentrate & 1.12 & 5.03 & 0.173 & 11.25 \\
\hline X15 & Pea protein isolate & 3.16 & 8.58 & 0.173 & 39.72 \\
\hline X16 & Soy flour & 0.82 & 4.52 & $0.083 \mathrm{a}$ & 8.69 \\
\hline X17 & Soy protein concentrate & 1.21 & 5.17 & 0.083 & 18.79 \\
\hline X18 & Soy protein isolate & 2.60 & 9.89 & 0.083 & 32.16 \\
\hline X19 & Wheat flour & 0.63 & 1.69 & $0.347^{\mathrm{a}}$ & 5.12 \\
\hline $\mathbf{X 2 0}$ & Wheat protein concentrate & 0.92 & 1.929 & 0.347 & 11.06 \\
\hline $\mathbf{X 2 1}$ & Wheat protein isolate (gluten) & 2.93 & 4.64 & 0.785 & 35.28 \\
\hline $\mathrm{X} 22$ & Eggs & $4.25^{\mathrm{c}}$ & $5.03^{\mathrm{c}}$ & $0.244^{\mathrm{b}}$ & 13.50 \\
\hline $\mathbf{X 2 3}$ & Cheese & $7.80^{\mathrm{d}}$ & $6.61^{\mathrm{d}}$ & $0.439^{\mathrm{b}}$ & $38.21^{\mathrm{d}}$ \\
\hline $\mathbf{X 2 4}$ & Meal worms & $2.65^{\mathrm{e}}$ & $3.56^{\mathrm{e}}$ & $0.003^{\mathrm{b}}$ & $33.68^{\mathrm{e}}$ \\
\hline X25 & Super worms & $2.65^{\mathrm{e}}$ & $3.56^{\mathrm{e}}$ & $0.003^{b}$ & $33.68^{\mathrm{e}}$ \\
\hline $\mathrm{X26}$ & Water & 0.00 & 0.00 & 0.000 & 0.00 \\
\hline $\mathbf{X 2 7}$ & Iron fortification & 0.30 & 2.00 & 0.010 & 5.00 \\
\hline $\mathrm{X} 28$ & B12 fortification & 0.30 & 2.00 & 0.010 & 5.00 \\
\hline $\mathbf{X 2 9}$ & Zinc fortification & 0.30 & 2.00 & 0.010 & 5.00 \\
\hline
\end{tabular}

922

Table C-3. Environmental data of chicken and beef (Blonk et al., 2007).

\begin{tabular}{llcc}
\hline & Unit & Chicken & Beef \\
\hline Climate change & $\mathrm{kg} \mathrm{CO}_{2}$ eq $/ \mathrm{kg}$ & $\mathbf{2 . 5 1}$ & $\mathbf{7 . 5 3}$ \\
Land use & $\mathrm{m}^{2} /$ year $/ \mathrm{kg}$ & $\mathbf{4 . 7 9}$ & $\mathbf{5 . 9 6}$ \\
Water use & $\mathrm{m}^{3} / \mathrm{kg}$ & $\mathbf{0 . 0 4 9}$ & $\mathbf{0 . 0 6 4}$ \\
Fossil depletion & $\mathrm{MJ} / \mathrm{kg}$ & $\mathbf{1 7 . 8 1}$ & $\mathbf{2 0 . 3 9}$ \\
\hline
\end{tabular}


926 Table D-1 shows the payoff matrices for the four environmental impact indicators. The matrices for

927 the vegetarian and the vegan chicken replacer are identical, because the optimal solutions for both

928 chicken replacers are the same. The highest values (underlined) of $Z_{c c}, Z_{l u}$ and $Z_{f d}$ occur when water

929 use $\left(Z_{w u}\right)$ is minimized, except for the fortification-free chicken replacer, where the highest value of $Z_{l u}$

930 occurs when fossil fuel depletion $\left(Z_{f d}\right)$ is minimized. The minimization of water use therefore has the

931 largest tradeoffs. Also for the beef replacers the water use has the largest tradeoffs.

932 Table D-1. Payoff matrices. The "*” indicate the lowest (best) value of $Z_{e}$ and the underlined numbers represent the highest

933 (worst) value of $Z_{e} . Z_{c c}=$ climate change (in $\mathrm{kg} \mathrm{CO}$ eq $\left./ \mathrm{kg}\right), Z_{l u}=$ land use $\left(\mathrm{m}^{2} /\right.$ year $\left./ \mathrm{kg}\right), Z_{w u}=$ water use $\left(\mathrm{m}^{3} / \mathrm{kg}\right), Z_{f d}=$ fossil

934 fuel depletion $(\mathrm{MJ} / \mathrm{kg})$.

\begin{tabular}{|c|c|c|c|c|c|}
\hline \multicolumn{6}{|c|}{ Vegetarian chicken replacer } \\
\hline & & \multicolumn{4}{|c|}{ Observed indicator } \\
\hline & & $Z_{c c}$ & $Z_{l u}$ & $Z_{w u}$ & $Z_{f d}$ \\
\hline \multirow{4}{*}{ 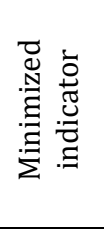 } & $Z_{c c}$ & $0.62^{*}$ & 2.64 & 0.040 & 9.31 \\
\hline & $Z_{\text {lu }}$ & 0.62 & $2.64^{*}$ & 0.040 & 9.31 \\
\hline & $Z_{w u}$ & $\underline{1.35}$ & $\underline{6.51}$ & $0.017^{*}$ & $\underline{15.78}$ \\
\hline & $Z_{f d}$ & 0.68 & 4.10 & $\underline{0.069}$ & $7.28^{*}$ \\
\hline
\end{tabular}

\begin{tabular}{|c|c|c|c|c|c|}
\hline \multicolumn{6}{|c|}{ Insect-based chicken replacer } \\
\hline & & \multicolumn{4}{|c|}{ Observed indicator } \\
\hline & & $Z_{c c}$ & $Z_{\text {lu }}$ & $Z_{w u}$ & $Z_{f d}$ \\
\hline \multirow{4}{*}{ 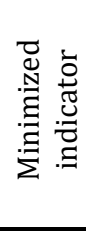 } & $Z_{c c}$ & $0.95^{*}$ & 2.84 & 0.035 & 13.32 \\
\hline & $Z_{l u}$ & 0.95 & $2.84^{*}$ & 0.035 & 13.32 \\
\hline & $Z_{w u}$ & $\underline{2.71}$ & $\underline{4.81}$ & $0.007^{*}$ & $\underline{34.10}$ \\
\hline & $Z_{f d}$ & 0.98 & 4.38 & $\underline{0.068}$ & $11.14^{*}$ \\
\hline
\end{tabular}

935

\begin{tabular}{|c|c|c|c|c|}
\hline \multicolumn{5}{|c|}{ Vegetarian/Vegan beef replacer } \\
\hline & \multicolumn{4}{|c|}{ Observed indicator } \\
\hline & $Z_{c c}$ & $Z_{l u}$ & $Z_{w u}$ & $Z_{f d}$ \\
\hline \multirow{4}{*}{ 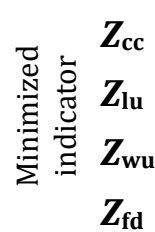 } & $0.59^{*}$ & 2.52 & 0.040 & 8.81 \\
\hline & 0.59 & $2.52^{*}$ & 0.040 & 8.81 \\
\hline & $\underline{1.31}$ & $\underline{6.32}$ & $0.019^{*}$ & $\underline{15.27}$ \\
\hline & 0.64 & 4.00 & $\underline{0.070}$ & $6.78^{*}$ \\
\hline
\end{tabular}

\begin{tabular}{|c|c|c|c|c|c|}
\hline \multicolumn{6}{|c|}{ Vegan chicken replacer } \\
\hline & & \multicolumn{4}{|c|}{ Observed indicator } \\
\hline & & $Z_{c c}$ & $Z_{l u}$ & $Z_{w u}$ & $Z_{f d}$ \\
\hline \multirow{4}{*}{ 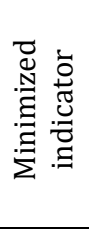 } & $Z_{c c}$ & $0.62^{*}$ & 2.64 & 0.040 & 9.31 \\
\hline & $Z_{l u}$ & 0.62 & $2.64^{*}$ & 0.040 & 9.31 \\
\hline & $Z_{w u}$ & $\underline{1.35}$ & $\underline{6.51}$ & $0.017^{*}$ & $\underline{15.78}$ \\
\hline & $Z_{f d}$ & 0.68 & 4.10 & $\underline{0.069}$ & $7.28^{*}$ \\
\hline
\end{tabular}

Fortification-free chicken replacer

Observed indicator

\begin{tabular}{|c|c|c|c|c|c|}
\hline & & $Z_{c c}$ & $Z_{l u}$ & $Z_{w u}$ & $Z_{f d}$ \\
\hline \multirow{4}{*}{ 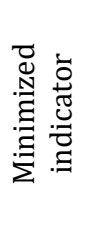 } & $Z_{c c}$ & $1.41^{*}$ & 4.25 & 0.103 & 9.81 \\
\hline & $Z_{l u}$ & 1.42 & $3.43^{*}$ & 0.083 & 11.36 \\
\hline & $Z_{w u}$ & $\underline{2.71}$ & 4.81 & $0.007^{*}$ & $\underline{34.10}$ \\
\hline & $Z_{f d}$ & 1.43 & 4.86 & 0.115 & $8.96^{*}$ \\
\hline
\end{tabular}

\begin{tabular}{|c|c|c|c|c|c|}
\hline \multicolumn{6}{|c|}{ Insect-based beef replacer } \\
\hline & & \multicolumn{4}{|c|}{ Observed indicator } \\
\hline & & $Z_{c c}$ & $Z_{l u}$ & $Z_{w u}$ & $Z_{f d}$ \\
\hline \multirow{4}{*}{ 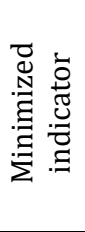 } & $Z_{\mathrm{cc}}$ & $0.91^{*}$ & 2.70 & 0.036 & 12.83 \\
\hline & $Z_{\text {lu }}$ & 0.91 & $2.69^{*}$ & 0.036 & 12.89 \\
\hline & $Z_{\mathrm{cc}}$ & $\underline{2.70}$ & $\underline{4.65}$ & $0.007^{*}$ & $\underline{34.05}$ \\
\hline & $Z_{\mathrm{fd}}$ & 0.95 & 4.28 & $\underline{0.069}$ & $10.63^{*}$ \\
\hline
\end{tabular}

936 
939 This sensitivity analysis investigates the effect of changing the environmental impact values of the

940 fortifications on the model results. The cost coefficient ranges of the environmental impact values are

941 determined, which represent the ranges of values for which the solution stays optimal (Hendriks,

942 2013). The upper bound of the values thus represent the maximum value for which the solution stays

943 optimal. Table E-1 shows the cost coefficient ranges of the environmental impact values of vitamin

944 B12 for the vegetarian/vegan chicken replacer. Tables E-2 to E-4 show the cost coefficient ranges of

945 the of the environmental impact values of relatively iron, vitamin B12 and zinc for the

946 vegetarian/vegan beef replacer. A can be seen from the tables, the upper bounds of the environmental

947 values are very high compared with the current values. The composition of the meat replacers are

948 therefore not sensitive for changes in cost coefficients and are thus quite robust.

949 Vegetarian/vegan chicken replacer

950 Table E-1. Cost coefficient ranges of environmental impact values of vitamin B12 fortification for the vegetarian/vegan

951 chicken replacer.

\section{Cost coefficient ranges vitamin $B 12$}

\begin{tabular}{lccc}
\hline & Current value & Lower bound & Upper bound \\
\hline $\mathrm{CC}(28)\left(\mathrm{kg} \mathrm{CO}_{2}\right.$ eq $)$ & 8.00 & 0.00 & $1.38 \mathrm{E}+06$ \\
$\mathrm{LU}(28)\left(\mathrm{m}^{2} /\right.$ year $)$ & 19.00 & 0.00 & $7.14 \mathrm{E}+05$ \\
$\mathrm{WU}(28)\left(\mathrm{m}^{3}\right)$ & 0.80 & 0.00 & $7.93 \mathrm{E}+04$ \\
$\mathrm{FD}(28)(\mathrm{MJ})$ & 52.00 & 0.00 & $3.11 \mathrm{E}+06$ \\
\hline
\end{tabular}

952

Table E-2. Cost coefficient ranges of environmental impact values of iron fortification for the vegetarian/vegan beef replacer.

\begin{tabular}{lccc}
\hline & \multicolumn{3}{c}{ Cost coefficient ranges iron } \\
\hline & Current value & Lower bound & Upper bound \\
\hline $\mathrm{CC}(27)\left(\mathrm{kg} \mathrm{CO}_{2}\right.$ eq $)$ & 8.00 & 0.00 & $2.15 \mathrm{E}+03$ \\
$\mathrm{LU}(27)\left(\mathrm{m}^{2} /\right.$ year$)$ & 19.00 & 0.00 & $7.26 \mathrm{E}+03$ \\
$\mathrm{WU}(27)\left(\mathrm{m}^{3}\right)$ & 0.800 & 0.00 & $3.92 \mathrm{E}+01$ \\
$\mathrm{FD}(27)(\mathrm{MJ})$ & 52.00 & 0.00 & $6.98 \mathrm{E}+03$ \\
\hline
\end{tabular}




\begin{tabular}{lccc}
\hline & \multicolumn{3}{c}{ Cost coefficient ranges vitamin B12 } \\
\hline & Current value & Lower bound & Upper bound \\
\hline $\mathrm{CC}(28)\left(\mathrm{kg} \mathrm{CO}_{2} \mathrm{eq}\right)$ & 8.00 & 0.00 & $1.38 \mathrm{E}+06$ \\
$\mathrm{LU}(28)\left(\mathrm{m}^{2} /\right.$ year $)$ & 19.00 & 0.00 & $7.21 \mathrm{E}+05$ \\
$\mathrm{WU}(28)\left(\mathrm{m}^{3}\right)$ & 0.800 & 0.00 & $7.93 \mathrm{E}+04$ \\
$\mathrm{FD}(28)(\mathrm{MJ})$ & 52.00 & 0.00 & $3.11 \mathrm{E}+06$ \\
\hline
\end{tabular}

Table E-4. Cost coefficient ranges of environmental impact values of zinc fortification for the vegetarian/vegan beef replacer.

\begin{tabular}{lccc}
\hline & \multicolumn{3}{c}{ Cost coefficient ranges zinc } \\
\hline & Current value & Lower bound & Upper bound \\
\hline $\mathrm{CC}(29)\left(\mathrm{kg} \mathrm{CO}_{2}\right.$ eq $)$ & 8.00 & 0.00 & $3.73 \mathrm{E}+02$ \\
$\mathrm{LU}(29)\left(\mathrm{m}^{2} /\right.$ year $)$ & 19.00 & 0.00 & $3.05 \mathrm{E}+03$ \\
$\mathrm{WU}(29)\left(\mathrm{m}^{3}\right)$ & 0.800 & 0.00 & $1.30 \mathrm{E}+02$ \\
$\mathrm{FD}(29)(\mathrm{MJ})$ & 52.00 & 0.00 & $2.85 \mathrm{E}+04$ \\
\hline
\end{tabular}

\section{Sensitivity lower bounds of iron and zinc}

Since the absorbability of non-heme iron and zinc depend on the presence of certain components in the diet the required content of iron and zinc in the meat replacer are uncertain. The required contents represent the lower bounds of the constraints for iron and zinc. It is investigated how changes in these lower bounds affect the optimal solutions. To do this, the slacks and shadow prices are calculated . The slacks represent how much the lower bounds can be increased without affecting the optimal solution. The shadow prices represent the increase in the objective value when the lower bound is increased with one unit. Table E-5 shows the current value, the slacks and the shadow prices of the lower bounds for the vegetarian/vegan chicken replacer. The shadow price is zero for both lower bounds and for all minimizations. This means that the zinc and iron constraints are both not binding (Hendriks, 2013). The slacks for both lower bounds are relatively high compared to the current values, so the optimal solutions are not very sensitive for changes in the value of the required content of iron and zinc. Table E-6 shows the current value, the slacks and the shadow prices of the lower bounds for the vegetarian/vegan beef replacer. The slacks are zero for both lower bounds and for all minimizations. This means that the zinc and iron constraints are binding. The shadow prices are quite high compared to the current values, which means that the results are sensitive for changes in required contents of iron, zinc and vitamin B12. 
979 Table E-5. Slacks and shadow prices of the lower bounds of zinc and iron for the vegetarian/vegan chicken replacer.

\begin{tabular}{llcccc}
\hline & & \multicolumn{4}{c}{ Minimized indicator } \\
& & CC & LU & WU & FD \\
\hline Required content iron & Current value & 2.03 & 2.03 & 2.03 & 2.03 \\
$(\mathrm{mg} / 100 \mathrm{~g})$ & Slack & 3.20 & 3.20 & 1.53 & 1.51 \\
& Shadow price & 0.00 & 0.00 & 0.00 & 0.00 \\
Required content zinc & Current value & 0.74 & 0.74 & 0.74 & 0.74 \\
$(\mathrm{mg} / 100 \mathrm{~g})$ & Slack & 1.36 & 1.36 & 2.20 & 2.22 \\
& Shadow price & 0.00 & 0.00 & 0.00 & 0.00 \\
\hline
\end{tabular}

980

981 Vegetarian/vegan beef replacer

982 Table E-6. Slacks and shadow prices of the lower bounds of zinc and iron for the vegetarian/vegan beef replacer.

\begin{tabular}{llcccc}
\hline & & \multicolumn{4}{c}{ Minimized indicator } \\
& & CC & LU & WU & FD \\
\hline Required content iron & Current value & 6.46 & 6.46 & 6.46 & 6.46 \\
$(\mathrm{mg} / 100 \mathrm{~g})$ & Slack & 0.00 & 0.00 & 0.00 & 0.00 \\
& Shadow price & 0.22 & 0.62 & 0.02 & 2.00 \\
Required content zinc & Current value & 6.45 & 6.45 & 6.45 & 6.45 \\
$(\mathrm{mg} / 100 \mathrm{~g})$ & Slack & 0.00 & 0.00 & 0.00 & 0.00 \\
& Shadow price & 0.22 & 0.60 & 0.01 & 1.07 \\
\hline
\end{tabular}

983 
985 Figure F-1 shows black and white version of figure 4 of Section 4.1.2.

Minsum
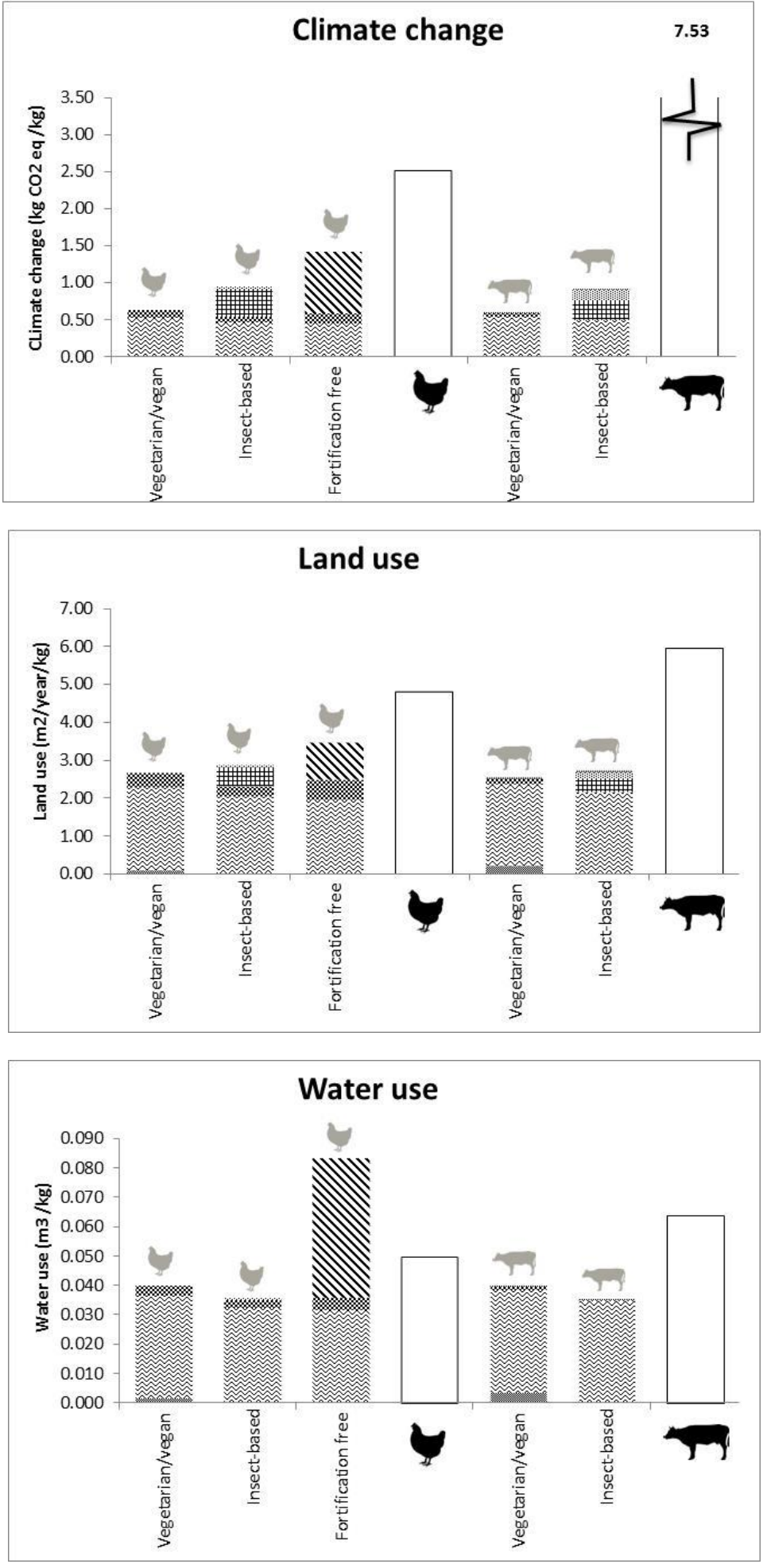

Minmax

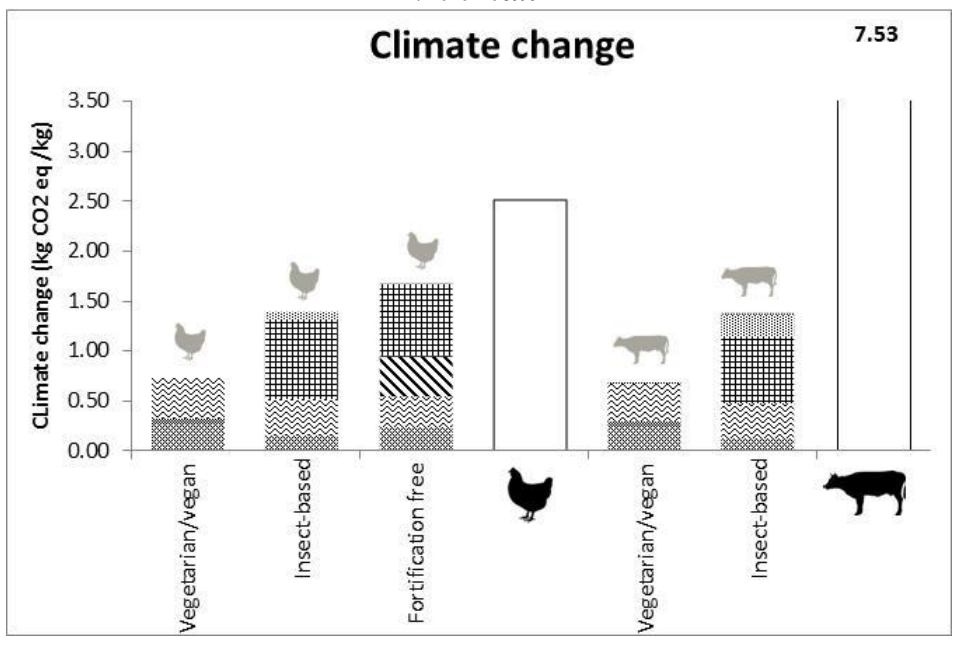

Land use

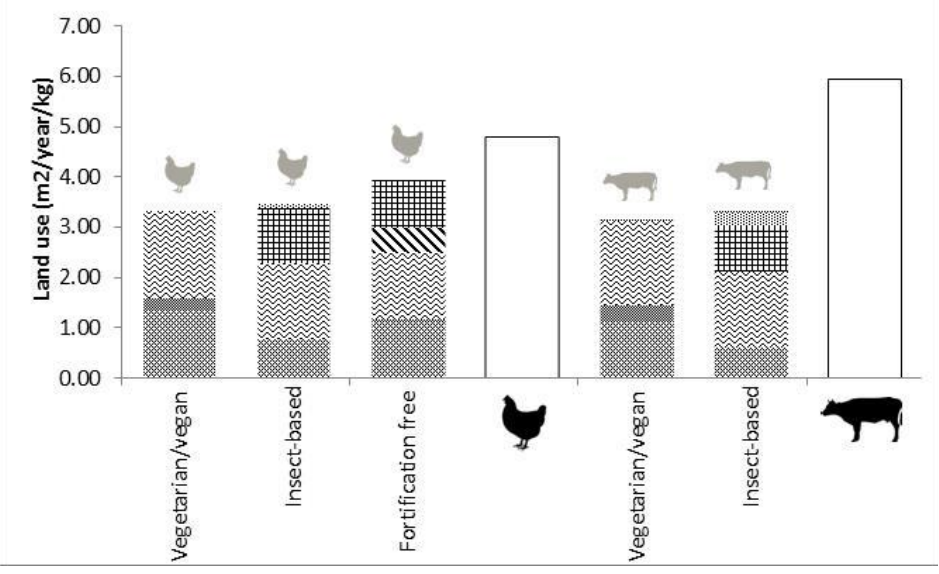

Water use

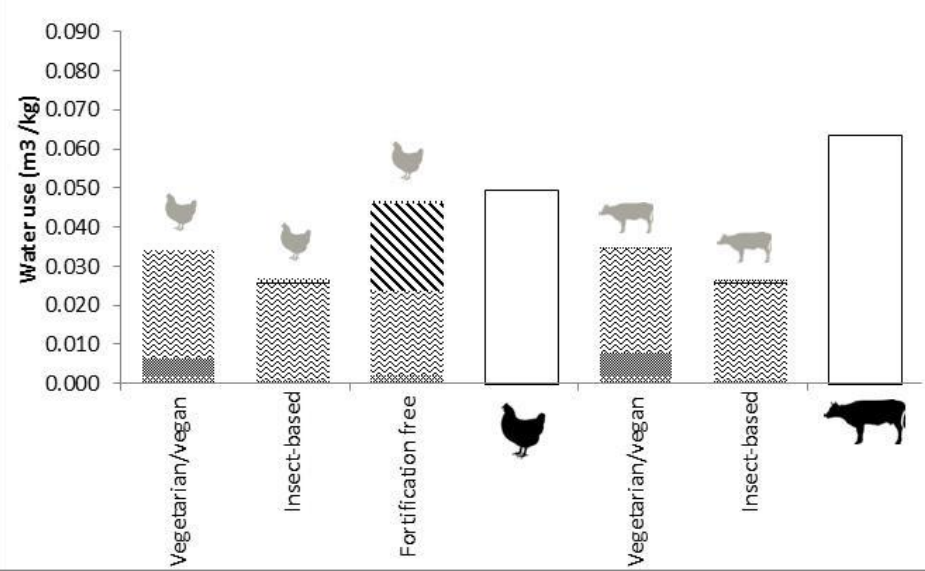



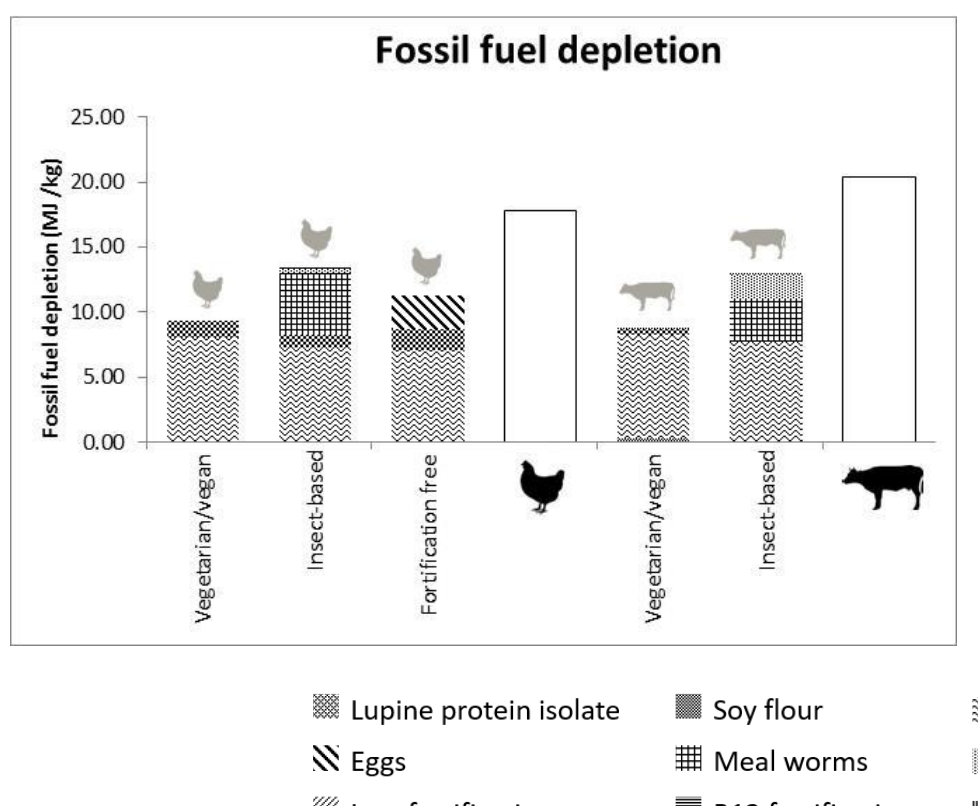

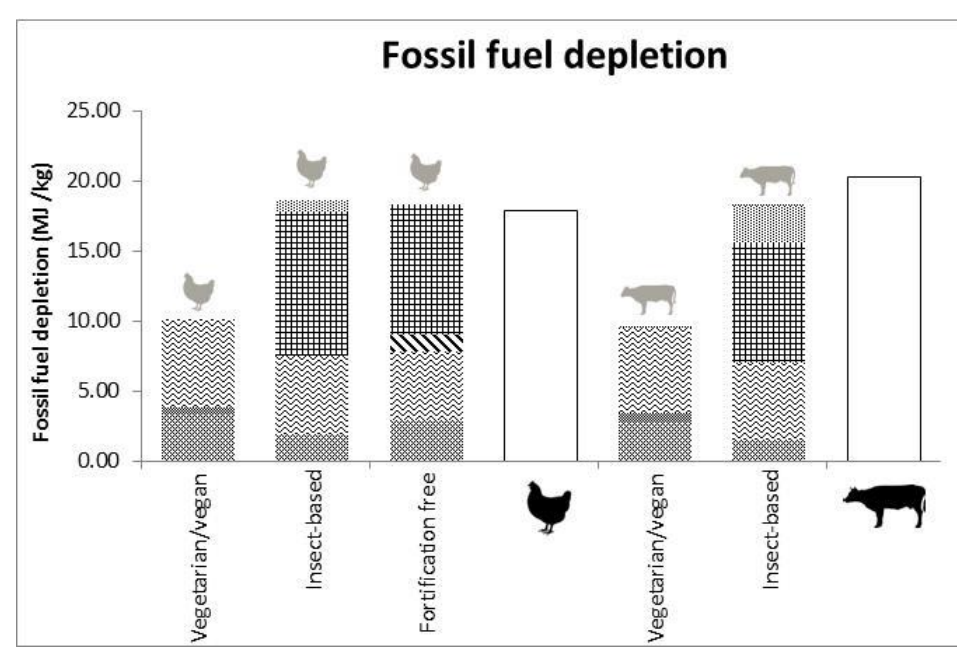
$\approx$ Soy protein concentrate Soy protein isolate
Ul Super worms
Water

||l||l| Zinc fortification
986

987

988
Figure F-1. Environmental impact values and contribution per ingredient, compared with the environmental impact values of chicken and beef, for minsum (left) and minmax (right) optimizations. The grey pictograms above the bars indicate which reference is used. The climate change value of beef $(7.53 \mathrm{~kg} \mathrm{CO} 2 \mathrm{eq} / \mathrm{kg})$ does not fit on the scale. 
990 Figure G-1 provides the composition of the chicken replacers and Figure G-2 provide the composition

991 of the beef replacers.

992 Table G-1. Compositions of the chicken replacers. Fortifications in mg/kg; all other ingredients in g/100g.

\begin{tabular}{|c|c|c|c|c|c|c|c|}
\hline & & \multicolumn{2}{|c|}{ Vegetarian/Vegan } & \multicolumn{2}{|c|}{ Insect-based } & \multicolumn{2}{|c|}{ Fortification-free } \\
\hline & & minsum & $\min \max$ & minsum & $\min \max$ & minsum & $\min \max$ \\
\hline$X_{12}$ & Lupine protein isolate & - & 8.7 & - & 5.0 & - & 7.4 \\
\hline$X_{16}$ & Soy flour & 1.7 & 5.0 & - & - & - & 0.5 \\
\hline$X_{17}$ & Soy protein concentrate & 42.2 & 33.3 & 38.9 & 29.5 & 37.7 & 25.9 \\
\hline$X_{18}$ & Soy protein isolate & 3.8 & - & 2.9 & - & 5.1 & - \\
\hline$X_{22}$ & Eggs & - & - & - & - & 19.5 & 9.1 \\
\hline$X_{24}$ & Meal worms & - & - & 14.2 & 30.6 & - & 27.5 \\
\hline$X_{25}$ & Super worms & - & - & 1.1 & 2.4 & - & - \\
\hline$X_{26}$ & Water & 52.2 & 52.9 & 43.0 & 32.6 & 37.7 & 29.6 \\
\hline$X_{28}$ & B12 fortification & 0.54 & 0.54 & 0.38 & 0.20 & - & - \\
\hline
\end{tabular}

993

994 Table G-2. Compositions of the beef replacers. Fortifications in $\mathrm{mg} / \mathrm{kg}$; all other ingredients in $\mathrm{g} / 100 \mathrm{~g}$.

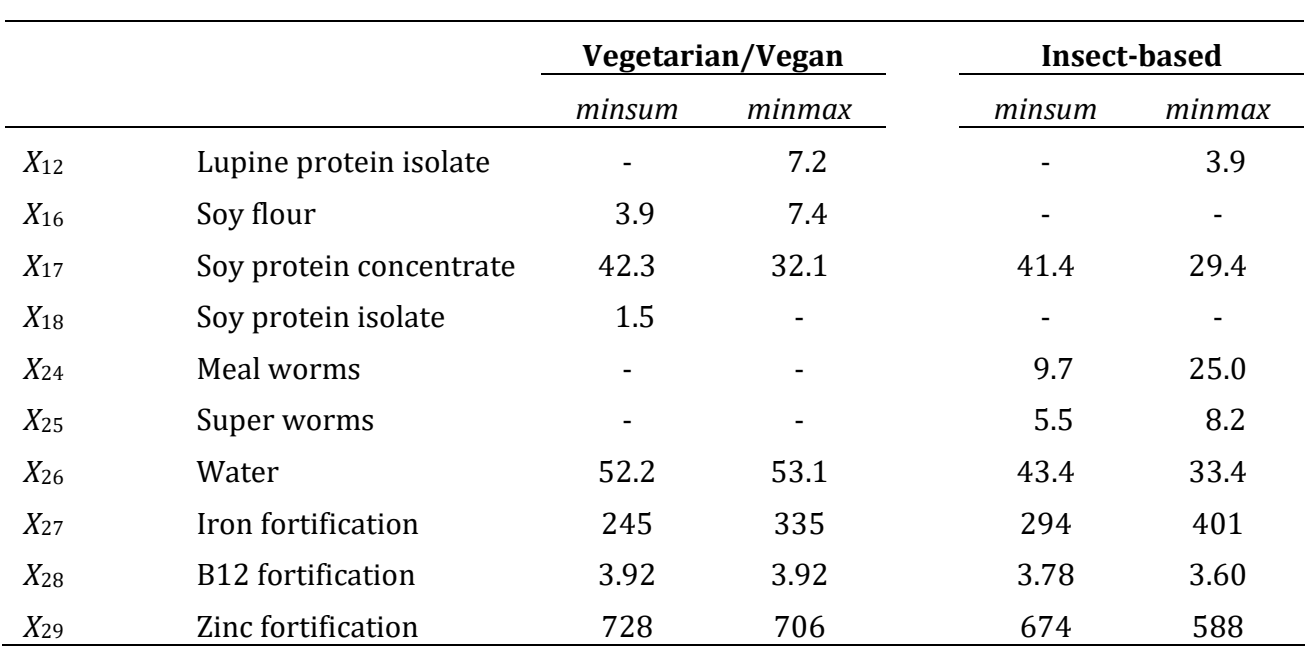

995 


\section{H. Environmental impact of soy}

In this study, soy emerges as one of the main ingredients for the meat replacer due to its high protein quality and low environmental impact values. However, the topic of soy production and its environmental impact are subject to controversy in the scientific literature and have been increasingly addressed over recent years. One of the main concerns associated with the production of soy is its role as a main driver of deforestation and its relation to direct and indirect land use change in areas such as Brazil's Amazon Basin, resulting in a substantial loss of Amazonian rainforest (Costa et al. 2007, Arima et al. 2011). Brazil's Amazonian rainforest plays an important part in mitigating climate change by storing carbon, which is released as a result of deforestation (Fearnside, 2016). Research suggests, that the destruction of the forest is has a significant impact on the Amazonian ecosystem and thus on biodiversity and climate regulation (Coe et al. 2013). Brazil is one of the main exporters of soy, alongside Argentina and the US, and supplies a large amount of the demand of feed for livestock systems in Europe and Asia (Billen et al. 2014). The growing demand of soy for global livestock, food as well as domestic biodiesel production in Brazil puts further pressure and incentives to increase soy production within the Amazon region (Costa et al., 2007; Lima et al. 2011).

\section{While there is a concern regarding the environmental impact of soy production within the Amazon} Basin, studies also show that the majority of deforestation can be attributed to pasture expansion (Barona et al., 2010; Macedo et al. 2011). However, these studies also show indications for linkages between increased soy production in the Mato Grosso region (former pasture area) and the pasture expansion further north, making soy production an underlying factor of deforestation. Furthermore, it should be noted that often, even though the land was cleared for soy, soy production only starts at a later stage while other crops or pastures are used to prepare the land (Lima et al., 2011, Gasparri et al. 2013), making it more difficult to allocate deforestation directly to soy production. When comparing land occupation by soybean production with pasture land occupation, Costa et al. (2007) show differences in the climate impact of both cases, with lower precipitation rates for soy due to larger surface albedo and lower evapotranspiration. Similar results are presented in the study of Sampaio et al. (2007).

Research shows that the environmental impact, associated to land use change of soy, as well as beef production, largely depends on the region as well as the methodology used to quantify land use change (Persson et al., 2014). Furthermore, there are large differences between individual production and transport scenarios. Da Silva et al. (2010) present differences in the environmental impact of soybean production in the Central West and the South of Brazil. Their results show, that impact values are generally higher in the Central West due to deforestation and transportation. A study by Castanheira and Freire (2013) also found variations between different cultivation systems of soy, in particular related to different land use change scenarios. Evaluating 45 different scenarios, the research shows 
variations of almost 150 to 200 times the amount of greenhouse gas emissions, with the lowest values found for degraded grassland in Argentina and the highest values related to systems associated with tropical rainforest conversion. Gasparri et al. (2013), however, find similar links between deforestation and soybean production in Northern Argentina's Dry Chaco, establishing soy as one of the main drivers of deforestation in the region. Similarly to Brazil, the deforestation in Argentina raises concerns in terms of the destruction of natural habitats as well as carbon storage (Viglizzo et al., 2011).

While there is evidence of soy being one of the main drivers of deforestation in South America, it should be noted that most of the soy produced in countries such as Brazil or Argentina is used for protein rich feed production to supply a growing demand of meat (Billen et al., 2014; Viglizzo et al., 2011). About $75 \%$ of soy is used to feed livestock (Aiking, 2011). In fact, soybean, produced in Argentina, Brazil and the USA with over half of the crop being genetically modified, is one of the main sources for animal feed, due to its high quality protein composition (FAO, 2004). However, the conversion of plant- based protein to animal protein is inefficient, with the possible exception of grassfed livestock (Sabaté and Soret, 2014). Research suggests that the conversion from plant to animal protein results in losses of around $85 \%$ with only $15 \%$ of the protein reaching the human consumption stage (Aiking, 2011). It should, however, be recognised that livestock systems possess the advantage to salvage, for human indigestible, by-products (soy-bean hulls) that otherwise might turn to waste and turn it into high quality protein (Wu et al., 2014). In this context, Van Kernebeek et al. (2016) argues that land is used most efficiently if $12 \%$ of the human dietary protein intake comes from animal sources that convert such by-products. Furthermore, the study of Sasu-Boakye et al. (2014) show, that using locally sourced feed can have a positive effect on the environmental impact of livestock production in Europe in comparison to feed based on soy sourced from South America.

1054 Based on these results, it is important to note that there are substantial variations in the environmental impact of soy and an increased production of soy alongside an increase in the consumption of meat is likely to pose a threat for the environment. However, so far, only a very small amount of soy protein is used for human consumption, with only about 2-3\% of total soy production being used for human food (Day, 2013). A reduction in intensive livestock production could reduce the demand for soy as feed and thus free agricultural land currently devoted to the production of animal feed. This newly available land could then be used to supply plant based protein for human consumption without requiring further land expansions and/or land use changes. However, for future scientific research there is a need to increasingly link the consumption and supply of food products while also looking into the different supply configurations within the system. 